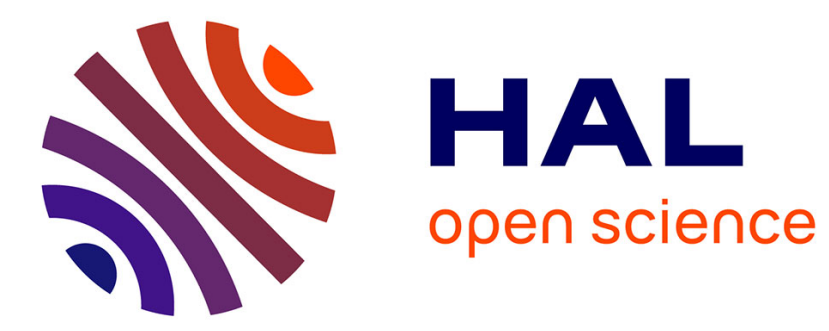

\title{
Resveratrol: preventing properties against vascular alterations and ageing.
}

Dominique Delmas, Brigitte Jannin, Norbert Latruffe

\section{To cite this version:}

Dominique Delmas, Brigitte Jannin, Norbert Latruffe. Resveratrol: preventing properties against vascular alterations and ageing.. Molecular Nutrition and Food Research, 2005, 49 (5), pp.377-95. 10.1002/mnfr.200400098 . hal-00376284

\section{HAL Id: hal-00376284 \\ https://hal.science/hal-00376284}

Submitted on 17 Apr 2009

HAL is a multi-disciplinary open access archive for the deposit and dissemination of scientific research documents, whether they are published or not. The documents may come from teaching and research institutions in France or abroad, or from public or private research centers.
L'archive ouverte pluridisciplinaire HAL, est destinée au dépôt et à la diffusion de documents scientifiques de niveau recherche, publiés ou non, émanant des établissements d'enseignement et de recherche français ou étrangers, des laboratoires publics ou privés. 


\section{Resveratrol : natural properties against atherosclerosis, associated pro-}

inflammatory effects and aging

Dominique Delmas, Brigitte Jannin and Norbert Latruffe

GDR-CNRS2583, IFR 92, Laboratory of Molecular and Cellular Biology, 6 boulevard Gabriel, 21000 Dijon

Running title: Vascular protective effects of resveratrol

\section{Whom all correspondence:}

Pr. Norbert Latruffe

GDR-CNRS2583, IFR 92, Laboratory of Molecular and Cellular Biology,

6 boulevard Gabriel,

21000 Dijon

Tél : 33380396236 or 0380396236

Fax. 33380396250 or 0380396250

E-mail : latruffe@u-bourgogne.fr

\section{Abbreviations :}

Keywords :

Resveratrol ; atherosclerosis ; inflammation ; aging ; antioxydant. 


\section{Introduction}

Vascular diseases including coronary heart disease (CHD), cerebrovascular and peripheral vascular diseases are the largest cause of mortality and morbidity in industrialized countries. Since many decades, various investigations have searched to identify the risk factors in cardiovascular diseases such as genetic factors, hypertension, and age. Some factoctors depend on our lifestyle such as smoking and diet. Indeed, diet high in fat and / or calories can lead to hypertriglyceridemia, a potent atherogenic risk factor. Besides a highenergy diet, certain unsatured fatty acids may be pro-atherogenic and pro-inflammatory, some nutrients may protect against vascular diseases and associated inflammatory effects. A protective effect may be obtained with a diet rich in vitamin $E$ [1], $\beta$-carotene [2], and in polyphenolic compounds found in fruits, vegetables and beverages. For example, in France, as compared with other western countries with a high-fat diet, the strinkingly low incidences of CHD have been attributed partly to the consumption of red wine, which contains high levels of polyphenols [3]. Similarly, benefic effects may be attributed to the flavonoids of green tea. Indeed, several cohort studies demonstrate a significant inverse association between flavonoid consumption and cardiovascular risk [4]. The benefic effects of these compounds seem to be due to their antioxidant/antiradical activities protecting the vascular walls from oxidation, from inflammation, from platelet aggregation and thrombus formation. Vascular wall stiffening is also age dependent, due to in part to an enhancement of oxidative stress. Among the polyphenols with benefic properties, resveratrol, a phytoalexin of grape, reproduces the effect of a caloric restriction on the aging phenomena [5, 6]. Many studies evaluate resveratrol as a protective factor of degenerative diseases. Resveratrol possess a myriad of cardiovascular benefic effects and can act at multiple levels such as cellular signaling, enzymatic pathways, apoptosis and gene expression.

\section{Resveratrol and atherosclerosis}

The main cause of the coronary damages and particularly ischemic vascular diseases is the atherosclerosis. Briefly, the atherosclerotic process is the result of disruptions of normal reactions between the blood (plasmatic proteins, lipoproteins, growth factors, lymphocytes, platelets) and the normal cellular elements of the arterial wall. So, various compounds can be act at different cellular levels to brake the atherosclerotic lesion formation and these new antiatherogenic drugs should be found in the diet. Indeed, various antioxidant compounds presents in food such as vitamin E, flavonoids and polyphenols, could be good candidats against atherosclerosis. Among this polyphenols, resveratrol could be a good agent acting at 
different stages of physiopathologic atherogenesis (lipid accumulation and low-density lipoproteins (LDLs) oxidation; monocyte and lymphocyte infiltration; cellular smooth muscle proliferation and migration, platelets aggregation).

\section{a) Resveratrol and lipoproteins}

Target disruption of the apolipoprotein E (apoE) or low-density lipoprotein receptor (LDLR) genes, as well as overexpression of the human apolipoprotein B (apoB) gene in mice, result in marked increases in VLDL (very low-density lipoprotein) and /or LDL levels and subsequently contribute to atherosclerosis promotion [7]. In hypercholesterolemic mice (apoE-/-/LDLR-/-), resveratrol decreases the plasma lipid concentrations (total cholesterol and triacylglycerols) and reduces platelet aggregates [8]. The plasmatic concentration of lipids can also be reduced by the action of other apolipoproteins such as apoB or apolipoprotein I/II (apo $\mathrm{I} / \mathrm{II}$ ). So, resveratrol is able to reduce apoB content and secretion (which may be responsible for impaired LDL and VLDL synthesis) as well as the intracellular content and the rate of secretion of cholesteryl esters from hepatoblastoma cells $[9,10]$. The rate of secretion of triglycerides (TGs) is also reduced by resveratrol, but the intracellular TGs content is unaffected. Taken together, these changes would tend to decrease the level of VLDLs which are riche in TGs and possess potential atherogenic properties (direct supply of cholesterol to fibroblasts; alterations of endothelial functions; transformation of monocytes-macrophages in foam cells). These events are found also in vivo in rats where resveratrol treatment dcreases serum TGs, VLDL+LDL-cholesterol levels [11]. By its estrogenic similar structure, resveratrol could act on apoII. Indeed, hepatic expression of apoII is in part modulated by estrogen-mediated stabilization of its mRNA which is due to the estrogen-regulated mRNA stabilizing factor (E-RmRNASF). E-RmRNASF protect the RNA from target endonucleolytic degradation and its hepatic expression is modulated by estrogenic xenobiotics. Resveratrol seems to act as phyto-estrogens and it appears that resveratrol acts as an agonistic compound stimulating the E-RmRNASF expression [12]. These results suggest that resveratrol would have the capacity to modulate and block certain aspects of hepatic lipoprotein metabolism which predispose to atherosclerosis and the hypocholesterolemic action of resveratrol could be attributed to an increased excretion of neutral sterols and bile acids into feces.

\section{b) Resveratrol and oxidative stress}

The second important event in the lesion formation is LDLs oxidation in the intima [13, 14]. Lipid peroxidation is a chain reaction process which can be induced by different freeradical sources (ionizing irradiation, UV light). Several groups have reported that oxidizedLDL (ox-LDL) can stimulate platelet aggregation [15] or promote procoagulant activity in the 
surface of human monocytes / macrophages by an increase in tissue thromboplastin activity [16] or by stimulating the expression and secretion of the tissue factor (TF) by monocytes or aortic endothelial cells [17].

Frankel et al, were the first to demonstrate that resveratrol added to human LDL, reduced the oxidation of human LDL induced by ncubation with a heavy metal ion such as copper [18]. This effect should be assigned to the chelation of copper because metals act as pro-oxidants by electron transfer, releasing free radicals from polyunsaturated fatty acids and hydroperoxides. It has been demonstrated that resveratrol suppresses lipid peroxidation both by chelation of copper [19-21] and by scavenging of the free radicals [19, 20, 22]. The efficiency and action mechanism of trans-resveratrol have been demonstrated in the radical liposome oxidation where it appeared that para-hydroxyl group shows a greater radicalscavenging activity than meta-hydroxyl groups of trans-resveratrol [23]. Moreover, the spatial position of hydroxyl groups is likely more propitious to the chelation of copper in the trans isomer than in cis isomer [20]. Due to its hydroxylated structure, resveratrol can form a radical derivative stabilized by the delocalisation of two electrons between the two aromatic cycles and the methylene bridge joining these two cycles. In addition to metal ion induced oxidation of LDLs, various enzymatic systems presents in endothelial cells (ECs) or macrophages are implicated in the oxidation of LDL (figure 2). These systems include nicotinamide adenine dinucleotide (NADPH) oxidases, hypoxanthine / xanthine oxidase (HX/XO), 15-lipoxygenase (15-LO), myeloperoxidase (MPO) and nitric oxide synthases (NOS) $[24,25]$. The products of these enzymes oxidize LDL which alter ECs, stimulate NADPH oxidase, the pro-inflammatory cytokines release, and inhibit endothelial nitric oxide synthase (eNOS) implicated in the vasorelaxation. So, resveratrol can act on these enzymes (figure 2).

$\mathrm{NAD}(\mathrm{P}) \mathrm{H}$ oxidases play an important role in superoxide production, $\mathrm{O}_{2}{ }^{--}$, in human vessels. Many cytosolic regulatory proteins (e.g. Rac) play an important part in regulating $\mathrm{NAD}(\mathrm{P}) \mathrm{H}$ oxidase activity in cardiovascular disease states by acute activation of the enzyme complex [26]. Resveratrol reduces the strain-increased $\mathrm{NAD}(\mathrm{P}) \mathrm{H}$ oxidase activity and $\mathrm{NAD}(\mathrm{P}) \mathrm{H}$ oxidase activity in rat aortic homogenates [27]. The isomer cis-resveratrol inhibits also NAD(P)H oxidase activity in macrophage homogenate [28]. These effects contribute to reduce intracellular reactive oxygen species (ROS) formation in EC caused by strain treatment. 
Resveratrol inhibits leukocyte adhesion induced by other superoxide-dependent stimuli such as $\mathrm{HX} / \mathrm{XO}$ which metabolize hypoxanthine, xanthine, and $\mathrm{NADH}$ to form uric acid, $\mathrm{O}_{2}{ }^{--}$ and $\mathrm{H}_{2} \mathrm{O}_{2}$ and platelet-activating factor [29].

Resveratrol is able to induce cellular antioxidants and phase 2 enzymes, including superoxide dismutase (SOD), catalase, glutathione peroxidase, glutathione-S-transferase, gluthatione reductase, NADPH:quinone oxidoreductase [27, 29, 30]. These results are also found in vivo. These modifications contribute to increase the resistance to cardiac cell injury elicited by ROS.

Resveratrol reduced the generation of $\mathrm{H}_{2} \mathrm{O}_{2}$, and normalized the levels of oxidizedglutathione reductase and MPO activities [31, 32]. MPO seemed to be important in vascular pathology because it change $\mathrm{H}_{2} \mathrm{O}_{2}$ to hypochlorous acid ( $\mathrm{HOCl}$ ) and other oxidizing species (figure 3). It also utilizes NO to generate ROS, thereby reducing NO bioactivity and increasing oxidative stress. By the normalization of the ROS levels, resveratrol limits the oxidative stress which inhibits NO synthesis by eNOS necessary for vasorelaxation (figure 3).

Oxidation induced by endothelial cells or by macrophages depends on lipoperoxides generated intracellularly and then transferred to the LDL. Cellular lipoxygenases, especially 15-lipoxygenase, appear to be involved [33, 34]. Various studies demonstrated that resveratrol inhibits lipoxygenases, in particular in human neutrophils where resveratrol strongly inhibits the 5- and 15-lipoxygenases producing in the arachidonate metabolism various proinflammatory products [35-38].

In addition to metal ions and ROS, ferrylmyoglobin and peroxynitrite are also potent oxidants implicated in oxidation of LDLs. Resveratrol was able to decrease the accumulation of hydroperoxides in LDL promoted by ferromyoglobin by reduction of the oxoferryl complex to metmyoglobin. Moreover the polyphenol inhibits LDL apoprotein modifications induced by peroxynitrite [39]. ROS production by polymorphonuclear leukocytes stimulated with formyl methionyl leucyl phenyalanine (fMLP) can be also strongly inhibited by resveratrol [40].

Moreover, resveratrol could act on targets in blood cells and in lipoproteins. Indeed, resveratrol was incorporated into blood cells and lipoproteins after in vitro incubations with plasma, lipoproteins and cells [41]. In fact, due to its lipophilic character, resveratrol is able to bind the lipoprotein particles suggesting that this event improved its anti-oxidant activity [42]. In lipoprotein particles, resveratrol is predominantly associated with their lipid moiety, but can be also associated with the protein moiety. Among plasma proteins, serum albumin could be involved [43]. This binding could explain that resveratrol reduce the oxidative alterations 
of lipid and protein moieties of LDL [19]. By protecting apoB domains involved in the receptor activity of cells, resveratrol could reduce the non-specific uptake of oxLDL by macrophages.

\section{c) Resveratrol and macrophages}

In normal conditions, the monocytes enter, through diapedesis, the subendothelial space, where they differentiate into macrophages (figure 2). Under endothelial dysfunction, circulating monocytes adhere to the arterial endothelium, migrate to the subendothelial space, and differenciate into resident macrophages within the subendothelial matrix. OxLDL stimulate the expression of scavengers receptors CD36 and the class A scavenger receptor (SR-A) within monocytes, macrophages and smooth muscle cells (SMC) (which normally do not express this receptor). These receptors internalize the oxLDL in a specific manner, leading to a massive accumulation of cholesterol esters until foam cells are formed. These macrophage-derived foam cells make up the fatty streak that precedes more advanced sclerotic lesions (figure 2).

Oxidative stress caused by phorbol esters or reactive oxygen up-regulates the SR-A in human SMC, which normally do not express this receptor [44]. Resveratrol inhibits the activity and the expression of SMC cyclooxygenase-2 (COX-2) which normally produced prostaglandin $\mathrm{E}_{2}\left(\mathrm{PGE}_{2}\right)$ which up-regulate SR-A expression [44]. Various growth factors such as interleukin-1 (IL-1), tumor necrosis factor alpha (TNF $\alpha$ ), epidermal growth factor (EGF), platelet-derived growth factor (PDGF), and transforming growth factor beta (TGF $\beta$ ) increase SMC SR-A activity [45]. Resveratrol could be able to decrease SMC SR-A activity through the action of these factors such as the decrease of EGF [46] (figure 2).

So, by the reduction of the interaction of oxLDL with macrophage scavenger receptors which play an atherogenic role, resveratrol contributes to prevent an early step in atherogenesis. At a molecular level, the acute formation of oxLDL-induced by ROS leads to the activation of mitogen-activated protein kinases (MAPK) pathways, which might be important for mitogenic signaling of oxLDL in VSMCs (see below figure 5). Resveratrol inhibits oxLDL-induced mitogenesis of VSMCs through the blocking of the ROS generation and the activation of the extracellular signal-regulated kinases (ERKs) pathway [47].

\section{d) Resveratrol and foam cell formation}

We have seen previously that oxLDLs favor the transformation of macrophages into foam cells [48]. The development of macrophage foam cells that contain massive amounts of cholesterol ester is a hallmark of both early and late atherosclerotic lesions. OxLDL derived cholesterol brought into the macrophage via scavenger receptors consists of free cholesterol 
as well as cholesterol esters that are hydrolyzed in lysosomes. In addition, oxLDLs stimulate ECs to produce chemokines, granulocyte and macrophage colony-stimulating factors [49] and they have direct chemotactic activity for monocytes to endothelium [50]. Resveratrol contributes to reduce the production of chemokines which may be responsible for the chemotaxis and accumulation of macrophages in fatty streaks (figure 3). Resveratrol is able to inhibit interleukin-6 (IL-6) release by stimulated peritoneal macrophages in mice [51, 52], and in cortical mixed glial cells [53]. This action could result from a calcium blocking of calcium ion influx by resveratrol (see further "resveratrol and platelet aggregation”). Moreover, resveratrol contributes to reduce inflammatory response in atherosclerosis when macrophages (or SMC, EC) appear to be activated and produce numerous inflammatory products, such as TNF $\alpha$, IL-6, monocyte chemoattractant protein-1 (MCP-1) (figure 3). Lesion progression is influenced by interactions between monocyte/macrophage and $\mathrm{T}$ cells. Lesional $\mathrm{T}$ cells appear to be activated, expressing both Th1 and Th2 cytokines [54] (figure 4). Resveratrol was able to inhibit the release of Th1-derived cytokines such as interferon $\gamma$ (INF $\gamma$ ) which stimulates macrophage production of pro-inflammatory cytokines, IL-2 production by splenic lymphocytes and TNF- $\alpha$ and IL-12 production by peritoneal macrophage [55-57] (figure 4). The expression of mRNA encoding MCP-1 was also blocked by resveratrol [58]. Resveratrol was also able to inhibit Th2-derived cytokines such as IL-4 which exerts antagonistic effects on INFy activity in macrophages and inhibition of Th1 cell function. Resveratrol inhibits the LPS-induced expression of IL-1mRNA in monocytes and ECs [59]. Concerning IL-8, the gene transcription as well as the protein production are inhibited by resveratrol [60].

This inhibition of cytokines production by the resveratrol is important for the regulation of adhesion molecule expression. Indeed, activated T lymphocytes and macrophages generate and release several cytokines with a number of biological effects on neighbouring cells [61]. So, various proinflammatory stimuli (e.g. interleukins, INF $\gamma$, TNF $\alpha$, LPS) induce the expression of vascular adhesion molecule-1 (VCAM-1) and intracellular adhesion molecule-1 (ICAM-1). These molecules mediate the firm adhesion of monocytes to the vascular endothelium in early atherosclerosis stages (figure 2 ou 3). Like others compounds of tyrphostine family which possess tyrosine kinase inhibitory activity [62, 63], resveratrol inhibits both the stimulated expression of VCAM-1 and monocyte adhesion to human vascular endothelial cells $[64,65]$. These effects also affect E-selectin and ICAM-1. Indeed, resveratrol decreased significantly the expression of ICAM-1 and VCAM-1 induced on endothelial cells by TNF- $\alpha$ or lipopolysaccharide (LPS) [66], as well as neutrophile and 
monocyte endothelial adhesion [67, 68]. This inhibition of adhesion molecule expression occurs at the same doses of resveratrol plasmatic concentrations ranging from $100 \mathrm{nmol} / \mathrm{L}$ to $1 \mu \mathrm{mol} / \mathrm{L}$ in rat $[64,69]$. It has been suggested that resveratrol may act as a rapid molecular signal interfering in the mechanism of VCAM-1 and ICAM-1 expression [70]. Vascular ECs can also to activated by proteolytic enzymes such as elastase which cause detachment or lysis of ECs and degradation of subendothelial matrices [71] and stimulate EC secretion of growth factors for SMC [72]. Resveratrol inhibits the release of both elastase and $\beta$-glucuronidase by polymorphonuclear leukocytes stimulated by fMLP and C5a and also inhibits their secretion [40]. So this modification of adhesion by resveratrol may support its use as an immunomodulating compound.

\section{e) Resveratrol and vascular smooth muscle cells}

Vascular smooth muscle cells (VSMCs) contribute to the pathogenesis of atherosclerotic lesions, since their proliferation and migration are critical events for progressive intima thickening and development of arterial wall sclerosis [73]. OxLDL can also promote the proliferation of the smooth muscle cells (SMC) which are in part resident intimal cells that preceded the lesions and in part their progeny that arose as a response to various stimuli (e.g. lipid accumulation, disruption of intimal sructure). Intima SMC accumulate large amounts of cholesterol esters and become foam cells (figure 4). Inhibition of VSMC proliferation may have a beneficial effect in retarding development of atherosclerotic disease.

Resveratrol could delay atherogenesis by inhibition of VSMCs proliferation [74, 75]. Indeed, resveratrol is able to reduce SMCs proliferation induced by diverse mitogens such as serum, endothelin and PGDF. The antimitogenic effects of resveratrol are not mediated by the induction of apoptosis, but appear to be related to a $\mathrm{G} 1 \rightarrow \mathrm{S}$ block in cell cycle traverse [76, 77] and the DNA synthesis [75]. In fact, resveratrol leads to a reversible arrest in early S phase of the VSMC cycle. About the molecular mechanism, it exists a controversery: Haider et al have shown that the VSMC cycle arrest was accompanied by an accumulation of an hyperphosphorylated retinoblastoma protein, a decrease of cellular levels of the cyclindependent kinase inhibitors p21(Cip1), p27(Kip1), and an enhancement of phosphorylated of p53 protein [77]. On the contrary, Mnjoyan and Fujise have shown that p21 and p53 are increased but this effect depends of resveratrol concentration [75]. Indeed, at lower concentration (6.25-12.5 $\mu \mathrm{M})$, resveratrol inhibits VSMCs proliferation without apoptosis described by Haider et al, but at higher concentration $(25 \mu \mathrm{M})$, resveratrol induces apoptosis in serum-stimulated VSMCs but not in quiescent VSMCs. These results suggest that resveratrol may be able to selectively eliminate abnormally proliferating VSMCs of the arterial walls in 
vivo. Resveratrol can also inhibits VSMCs proliferation induced by AGEs (Advanced Glycation End-product) of plasma proteins and/or matrix proteins which are mediators implicated in various vascular complications [78]. AGEs increase coagulation through various mechanisms involving the vascular endothelium and platelet activation [79]. AGEs also increase DNA synthesis and propyl hydroxylase activity, a marker of collagen synthesis in stroke-prone spontaneously hypertensive rats (SHRSP) or Wistar-Kyoto rats (WKY) VSMCs. These phenomenon are inhibited by resveratrol in animal experimental model [80]. In this same perspective of fighting against atherosclerosis process, it has been shown that the inhibition of pulmonary artery endothelial cells proliferation by resveratrol is correlated with the suppression of cell progression through S and G2 phases of the cell cycle [81, 82].

\section{f) Resveratrol and vasorelaxation}

Resveratrol was able to inhibit the production of endogenous vasoconstrictors and thereby regulates vasomotion which is impaired in atherosclerosis. The key regulators of vasomotor function are the vasodilatator NO and the vasoconstrictor endothelin-1 (ET-1). In VSMC, oxidative stress increases the ET-1, which is involved in endothelial dysfunction, generation and autocrine ET-1 activity. Resveratrol inhibits strain-induced ET-1 secretion [83, 84], ET-1 mRNA level, and ET-1 promoter activity [84]. This inhibition of strain-induced ET-1 gene expression was partially due to resveratrol attenuation of activator protein 1 (AP-1) binding activity and resveratrol interference in the ERK1/2 pathway through attenuation of ROS formation [84] (figure 5). Resveratrol inhibits ET-1 surproduction and cytosolic phospholipase $\mathrm{A}_{2}\left(\mathrm{PLA}_{2}\right)$ activity stimulated by oxidative stress [83]. ET-1 expression can be induced by several substances such as angiotensin II (Ang II), thrombin, PDGF-A, and TNF $\alpha$ [85]. So, resveratrol can reduce ET-1 expression by its action on the latter factors. Indeed, resveratrol can act on Ang II. Angiotensin II-induced hypertrophy of vascular VSMCs is a pivotal step in the development of CHDs. Resveratrol could fight angiotensin II (Ang II)induced VSMC hypertrophy by interfering with the phosphatidylinositol 3-protein (PI3K)/Akt and p70 ribosomal protein S6 kinase (p70(S6K)) [77, 86]. Indeed, resveratrol is able to attenuate the phosphorylation of $\mathrm{p} 70(\mathrm{~S} 6 \mathrm{~K})$ as well as the phosphorylation of Akt/ protein kinase B (PKB) and ERK1/2, both essentially involved in Ang II-mediated hypertrophy (figure 5). This action on Ang II by resveratrol can protect from cardiac fibrosis. Indeed, cardiac fibrosis results of a prolonged activation of cardiac fibroblats (CFs) leading to a reduction of myocardial contractile function. Resveratrol inhibits Ang II-induced ERK1/2 and ERK kinase activation in CFs [87]. Moreover, pretreatment of CFs with resveratrol reduced both Ang II- and TGF $\beta$-induced CF differenciation to the myofibroblast phenotype, indicated 
by a reduction in alpha-smooth muscle actin expression and stress fiber organization in CFs. So, resveratrol appeared to act as an anti-fibrotic agent in the myocardium. Furthermore, the reduction of Ang II concentrations would reduce the increase of NADPH oxidase-derived ROS.

ET-1 activates specific receptors, designated as $\mathrm{ET}_{\mathrm{A}}$ and $\mathrm{ET}_{\mathrm{B}}$ [88]. So, resveratrol by its action on PLA 2 and other signalling pathways appears to protect against VSMC contraction mediated by the $\mathrm{ET}_{\mathrm{A}}$-receptor.

The inhibition of strain or the induction of vasorelaxation can also be dependent on NO production, $\mathrm{Na}^{+}$concentrations or cGMP pathways. For the NO production, it has been clearly documented that resveratrol can modulate the level of NO by its action on both eNOS and iNOS. Under normal conditions, ECs produce NO at a low level to control vessel dilatation. However, in atherosclerosis, a high level of NO has been found within early lesions and advanced atheroma even though expression of eNOS is reduced. On the contrary, the inductible Ca2+-independent NOS, also known iNOS, was increased. It has been shown that resveratrol can cause NO-mediated relaxation of precontracted endothelium-intact rat aorta through an increase of NO via eNOS [89-93]. At molecular level, resveratrol enhanced eNOS expression and inhibited iNOS expression by an action on their promoter (see below resveratrol and nuclear targets). In fact, resveratrol increases the activity of the eNOS promoter and eNOS mRNA stabilisation [94]. The vasorelaxation mediated by the polyphenol was reversed by the constitutive $\mathrm{Ca}^{2+}$-dependent NOS (cNOS). The compound also induces a NO-independent vasodilatation on denuded aorta, and the vasorelaxative activity of resveratrol depends also on direct stimulation of $\mathrm{K}^{+} / \mathrm{Ca}^{2+}$ channels in ECs [95]. So, it seems that the ability of resveratrol to modulate calcium channels in ECs could contribute to control the vasorelaxion mediated by nitric oxide (NO) (see below resveratrol and platelet aggregation).

Concerning the cGMP pathway, resveratrol increases cGMP in coronary arteries, mostly by activation of pGC [96]. Resveratrol activates membrane-bound guanylate cyclase GC-A, the receptor for atrial natriuretic factor (ANF) [97]. At molecular level, the cGMP/kinase-G is an antiproliferative signaling in SMCs and it dilates blood vessels through the reduction of intracellular calcium. The cytotastic actions of cGMP in SMCs involved apoptosis, inhibition of PI3K and mitogen-activated protein kinases (MAPKs) interfering with the cell-cycle machinery [98]. So the activation of pGC by resveratrol triggers vasorelaxant responses that remain effective in endothelium-disrupted arteries. 
Resveratrol could also influence the vasorelaxation through an action on the activity of $\mathrm{BK}(\mathrm{Ca})$ channels which are functionally expressed in vascular ECs; it controls $\mathrm{K}^{+}$efflux and affects intracellular $\mathrm{Ca}^{2+}$ concentration. In fact, resveratrol opens large and small conductance $\mathrm{Ca}^{2+}$-activated $\mathrm{K}^{+}$(BKCa) channels, but not ATP-sensitive $\mathrm{K}^{+}$channels [99] and increases the activity of large conductance BKCa channel in ECs $[95,100]$. The resveratrol-stimulated increase in the channel activity was independent of internal $\mathrm{Ca}^{2+}$. So, the increase in $\mathrm{K}^{+}$efflux through resveratrol-induced stimulation of KCa channels in ECs may contribute to produce vasorelaxation.

\section{g) Resveratrol and angiogenesis}

Angiogenesis is important in atherosclerosis where EC migration, proliferation are essential events in this process. Vascular endothelial growth factor (VEGF) co-localizes with endothelial cells, macrophages and SMC in atherosclerotic plaques [101]. Resveratrol inhibits VEGF-induced angiogenesis by abrogating VEGF-mediated tyrosine phosphorylation of vascular-cadherin and its complex partner, $\beta$-catenin [102]. The inhibition of VEGF-induced angiogenesis is mediated by the disruption of ROS-dependent Src kinase activation and the subsequent VE-cadherin tyrosine phosphorylation. Resveratrol can also reduce VEGF by its action on NADPH oxidase [27, 28] which regulates the induction of VEGF expression [103] and the VEGF-induced angiogenesis [104]. VEGF expression can be also regulated by proapoptotic factors such as AngII, which may be accumulated in response to ECs damage. Consequently to its effect on Ang II, resveratrol can inhibit Ang II-mediated VEGF expression [86]. Furthermore, it inhibits both the FGF (fibroblast growth factor) receptor- and the VEGF receptor-mediated EC responses [105].

\section{h) Resveratrol and platelet aggregation / thrombosis}

Platelets contribute to the rate of development of atherosclerosis and CHD through several mechanisms. It has been shown that resveratrol reduces platelet aggregation in human platelet-rich plasma in particular after induction by thrombin and adenosine-5'-diphosphate (ADP) treatment [106-108]. These in vitro results can were found again in vivo [109]. In fact, thrombin downregulates endothelial ectonucleotidase activity resulting in high level of ADP and ATP which lead to platelet and endothelial activation. Resveratrol inhibits thrombininduced ADP and ATP secretion from platelets, decreases neutrophil function and restores the CD39/ATPDase (ATP diphosphohydrolase) in response to thrombin [110]. Furthermore, when activated by thrombin, platelets produce ROS. This free radical generation can be reduced by resveratrol in blood platelets [111, 112]. In addition to thrombin and ADP another factor, platelet-activating factor (PAF), has been reported to be also involved in atheromatosis 
generation. Resveratrol was able to inhibit PAF-induced platelet aggregation [113] and its pro-inflammatory effects [29]. The PAF-induced platelet aggregation is accompanied by the release of thromboxane $A_{2}\left(T_{x} A_{2}\right)$, a pro-aggregant and vasoconstrictor agent. Moreover, PAF stimulates polymorphonuclear leukocytes to aggregate, to release leukotrienes and to generate superoxide. Similarly, PAF promotes aggregation of monocytes. So, reveratrol inhibiting PAF effects can reduce the effects of pro-aggregants / pro-inflammatory agents such as eicosanoids and leukotrienes.

The synthesis of eicosanoids and leukotrienes from arachidonic acid is also linked to the platelet aggregation. The synthesis of products from arachidonic acid in human platelets occurs according to several pathways. The lipoxygenase pathways lead to hydroperoxyeicosatetraenoic acids (HPETE) which are unstable and may be converted to their corresponding hydroxy fatty acids (HETE). The cyclooxygenase (COX) and the prostaglandin $\mathrm{H}$ synthase (PHS) pathways lead to the cyclic endoperoxides and the subsequent metabolic products such as $\mathrm{TxA}_{2}$.

Resveratrol is able to act on lipoxygenase family. Resveratrol inhibits both 5lipoxygenase and 15-lipoxygenase as a competitive inhibitor [38]. Resveratrol prolonged the lag phase of both enzymes, indicating a possible reduction of $\mathrm{Fe}(\mathrm{III})$ to $\mathrm{Fe}(\mathrm{II})$ at the catalytic site [114]. Pinto et al have shown that resveratrol inhibits the dioxygenase activity of lipoxygenase and is simultaneously oxidized by the peroxidase activity of lipoxygenase. The oxidized form of resveratrol is a lipoxygenase inhibitor as efficeint as the reduced form [37, 115]. This lipoxygenase inhibition by resveratrol prevents the release of pro-inflammatory substances such as 5-hydroxy-6,8,11,14-eicosatetraenoic acid (5-HETE), 5,12-dihydroxy6,8,10,14-eicosatetraenoic acid (5,12-diHETE), 12-hydroxyeicosapentaenoic acid (12 HETE), leukotriene B4 (LTB4) and its isomers (6-trans-LTB4, 12-trans-epi-LTB4) and its glutathione-conjugated derivative (LTC4) [35, 40, 116]. The 12-lipoxygenase pathway of arachidonate metabolism, which is present in leukocytes and platelets, can be reduced by resveratrol, which blocks the synthesis of hepoxilins, mediators of calcium mobilization, vascular permeability and neutrophil activation $[117,118]$.

Resveratrol is also a competitive inhibitor of COX and peroxidase activity of PHS [38]. As far as PHS is concerned, both COX and peroxidase activities depend on ferriprotoporphyrin IX $[119,120]$. Again, the prolonged lag phase of the COX reaction was indicative of a reduction of Fe(III) to Fe(II) [120, 121]. The COX inhibition by resveratrol prevents the release of COX products such as prostaglandins and thromboxanes. For example, the polyphenol reduces the prostaglandin synthesis, decrease HHT, $\mathrm{TxA}_{2}$ as well as $\mathrm{TxB}_{2}$ 
synthesis which are proaggregant and vasoconstrictor agents [35, 118, 122, 123]. By inhibition of PLA$A_{2}$, resveratrol decreases the release of arachidonate from cell lipids and thus the synthesis of metabolites by COX and lipoxygenase pathways [123]. Moreover, the polyphenol could act on the $\mathrm{Ca}^{2+}$ influx, subsequently reducing the activation of $\mathrm{PLA}_{2}$ and the aggregation process. Indeed, an increase in intracellular free $\mathrm{Ca}^{2+}$ is an essential component of the aggregation process in platelets. $\mathrm{Ca}^{2+}$ must enter the cell from the external media through specific and tightly regulated $\mathrm{Ca}^{2+}$ channels in the plasma membrane. It appears that resveratrol is an inhibitor of store-operated $\mathrm{Ca} 2+$ channels and calcium influx in thrombinstimulated human platelets [124-126]. Moreover, the blocking of calcium ion influx into cultured murine macrophages by resveratrol is one of the possible mechanisms of the proinflammatory IL-6 biosynthesis inhibitory action of resveratrol [51]. Nevertheless, Slater et al. [127] found that the inhibition of PKC $\alpha$ activity is competitive with respect to phorbol ester concentration but non competitive with respect to $\mathrm{Ca} 2+$ and phosphatidylserine concentrations suggesting that resveratrol compete for phorbol ester binding site to the $\mathrm{C} 1$ domains.

$\mathrm{Ca}^{2+}$ regulates various pathways and is a major second messenger implicated in signal transduction pathways regulating cell cycle, proliferation and apoptosis. Several proatherogenic stimuli induce ECs apoptosis through $\mathrm{Ca}^{2+}$-dependent pathways and contribute to the development of vascular lesions. OxLDL-mediated endothelial cells apoptosis is dependent on an increase in intracellular $\mathrm{Ca}^{2+}[128]$. Thus, alterations in intracellular $\mathrm{Ca}^{2+}$ in ECs may cause EC dysfunction in response to oxLDL and may influence EC response to oxLDL and inflammatory cytokines, particularly TNF- $\alpha$. Resveratrol blocking the $\mathrm{Ca}^{2+}$ influx could prevent the EC apoptosis. Several matrix elements play also an important role in platelet aggregation such as collagen and fibrinogen. Resveratrol was shown to block the first step of platelet activation by inhibiting platelet adhesion to type I collagen and to decrease collagen-induced platelet aggregation [129, 130] (figure 4). Moreover, resveratrol inhibited the messenger RNA (mRNA) expression of type I collagen [131]. At cellular level, in the platelets, resveratrol can inhibit MAPK activation induced by collagen, thrombin and ADP [132] (figure 5). So, resveratrol could block receptor-mediated signaling events in platelets.

Concerning the blood platelet adhesion to fibrinogen, another initial step of platelet activation, resveratrol inhibits adhesion of both thrombin- and ADP-activated platelets to fibrinogen [133] or after activation by LPS or LPS with thrombin [130, 134]. Moreover, resveratrol could protect against atherosclerosis by promoting fibrinolysis. Indeed the polyphenol such as others compounds (catechin, epicatechin) is able to up-regulate both 
tissue-type plasminogen activator (t-PA) and urikinase-type PA (u-PA) gene transcription which are fibrinolytic proteins [135].

Thrombosis plays a critical role in the development, progression and clinical aftereffects of atherosclerosis. The primary initiator of thrombus that mostly consisted of platelet aggregates, is a cell surface receptor for factor VII (a), the tissue factor (TF) [136]. The reduction of TF expression in vascular cells, ECs and monocytes may also contribute to the anti-aggregatory effects of resveratrol [59, 137] (figure 4). In fact, resveratrol reduced TF activity, TFmRNA by inhibition of nuclear factor kappa B (NFkB) / Rel-dependent transcription by impairing the transactivation potential of p65 [137, 138]. The diminution of c-Rel/p65 activity was dependent upon inhibition of degradation of the c-Rel/p65 inhibitory I $\mathrm{B} \alpha$ (inhibitor of $\kappa \mathrm{B}$ ) [138] (figure 5). The anti-thrombosis properties of resveratrol have been also showw in vivo. Indeed, resveratrol orally administrated with a high-fat diet in genetically hypercholesterolemic mice (apoE-/-/LDLR-/-) suppressed the formation of atheroma in the aortae and reduced the laser-induced thrombosis in their carotid arteries [8].

\section{i) Resveratrol and cellular / nuclear targets}

Specific non-antioxidant effects of resveratrol in cellular signaling and regulation of gene expression have been studied and have an important impact on atherosclerosis development.

Resveratrol was able to act on the MAPK cascade. Downstream targets for the action of MAPKs comprise mitogenic/pro-inflammatory enzymes and nuclear transcription factors (figure 5). Resveratrol is able to act at different levels. Indeed, resveratrol is able to act on upstream pathway by inhibiting the phosphorylation and the activity of PKC $[127,139,140]$. Resveratrol inhibits PKC-catalyzed phosphorylation of arginin-rich protein substrate in a non competitive manner [141]. The potency of resveratrol depends on the nature of the substrate and cofactors [141]. As diacylglycerol, resveratrol interacts with the C1 domains and induces the association of PKC $\alpha$ with membrane vesicles. Resveratrol can also inhibit other kinases such as Src which activates MAPK cascade [102]. Resveratrol inhibits also the PI3K phosphorylation and prevents the Akt / protein kinase B (PKB) phosphorylation. Consistent with this action, resveratrol attenuates the phosphorylation of $\mathrm{p} 70^{\mathrm{S} 6 \mathrm{~K}}$ which was shown in VSMC to require both the Akt / PKB and the ERK signaling cascades [86]. Consequently, resveratrol disturbs the protein synthesis because $\mathrm{p} 70^{\mathrm{S} 6 \mathrm{~K}}$ plays a critical role in regulating the translation of mRNAs. Resveratrol downregulates MAPK cascade by inhibiting the tyrosine phosphorylation of ERK1/2/JNK/p38 and the translocation into nucleus in the vascular cells 
[47, 84, 142]. This inhibition of phosphorylation and of translocation into nucleus from cytoplasm, reduces the expression of various genes implicated in the vasoconstriction, angiogenesis, proliferation, differenciation. In addition to its action on MAPK cascade, the polyphenol affects nuclear factors and consequently the gene expression. Its affects NFkB which activates the transcription of several target genes implicated in initiation and progression of pathogenesis in atherosclerosis, in inflammation, as well as in cancer [143]. Many stimuli such as oxLDL, ROS, PKC, have the potency to activate the NFאB pathway. $\mathrm{NF} \kappa \mathrm{B}$ is located in the cytoplasm as an inactive complex when associated with the inhibitor of $\kappa \mathrm{B}(\mathrm{I} \kappa \mathrm{B})$. In response to stimuli, the catalytic subunits of I $\mathrm{B}$ kinase (IKK) complex phosphorylate $\mathrm{I} \kappa \mathrm{B} \alpha$ at two conserved serines. This phosphorylation event triggers the ubiquitin-dependent degradation of IאB by the $26 \mathrm{~S}$ proteasome. Active p50/p65 complex is subsequently activated by phosphorylation of IKK $\alpha$ and PKC resulting in nuclear translocation of p50/p65 heterodimers (figure 5). The nuclear NFאB then binds to specific $\kappa \mathrm{B}$ DNA motifs and modulates the transcription of target genes (e.g. COX, iNOS, cytokines, ...).

The first study on the effect of resveratrol on NFkB showed that treatment with oxLDL and VLDL activate NFkB binding activity and that resveratrol attenuates the activation of NFkB in PC-12 cells [144]. Furthermore, thanks to its properties of ROS scavenger and PKC inhibitor, resveratrol blocks stimuli-mediated phosphorylation and degradation of IкB $\alpha$ as well as the activation of IKK $\alpha$ (figure 5) [58, 145, 146]. Resveratrol inhibits the phosphorylation of p65 and its transactivation [137] by inhibiting kinases such as IKK $\alpha$ [145], PKC [127] and the intrinsic kinase of PKC $\delta$ [147]. A recent study shows that a long treatment with resveratrol in human umbilical vein endothelial cells increases tyrosine

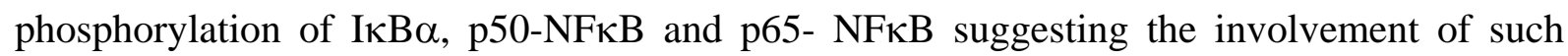
alterations in the modulation of NFאB transcription activity [148]. It has been also reported

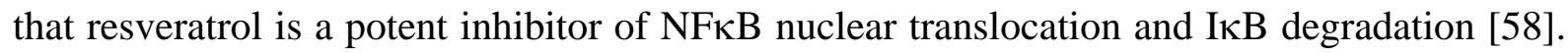
Resveratrol blocks the translocation of the p65 subunit of NFкB in inflammatory agents (TNF $\alpha$, PMA, LPS, $\mathrm{H}_{2} \mathrm{O}_{2}$ )-stimulated cells resulting in reduced transcriptional activity [146]. GATA and AP-1 are also affected by resveratrol. Indeed, the suppression of NFkB by resveratrol coincides with the inhibition of activator protein-1 (AP-1) [149]. In fact, resveratrol inhibits stimuli-induced AP-1-mediated activity [146, 150, 151] through the inhibition of c-Src non-receptor tyrosine kinase [152] and MAPK pathways such as MEKK1 and JNK [146, 152], which can activate both AP-1 and NFkB pathways [153, 154]. 
Moreover, resveratrol reduces the DNA binding activity and transcriptional activities of AP-1 and its composition [60, 84, 155]. The disturbing of the nuclear factors (e.g. NFkB, AP-1, GATA,...) by resveratrol affects the genes expression. In particular two genes, iNOS and COX-2, are involved in the CHD process. Concerning the iNOS gene, its expression is controlled, in part, by NFKB [156]. So, resveratrol is able to inhibit iNOS expression in various cell types [157-162], in particular in macrophages regulating blood pressure where resveratrol inhibits iNOS and down-regulates NFאB [161]. Concerning COX-2, various reports demonstrate the presence of COX-2 expression by SMCs in human atherosclerotic lesions [163, 164], and its expression is also regulated by various nuclear factors such as NFkB, AP-1, c-Jun [165]. Many studies demonstrated that resveratrol inhibits COX expression via an action on the nuclear factor such as AP-1, c-Jun [150, 151, 166, 167]. Moreover, docking studies on both COX-1 and COX-2 protein structures also revealed that hydroxylated but not methoxylated resveratrol analogues are able to bind to the previously identified binding sites of the enzymes [168]. This down-regulation of COX-1/2 genes expression by resveratrol is correlated with a decrease of inflammation [122]. Indeed, the inflammatory aspect of atherosclerosis include the COX-dependent prostaglandin cascade, and so resveratrol decreases the level of prostaglandin by a reduction of COX-2 activity. Resveratrol can also act on COX-1/2 via the peroxisome proliferator-activated receptor (PPAR). In human VSMC a PPAR $\alpha$ agonist has been shown to decrease NFkB activity [169]. Decreased NFאB activity reduces COX-2, so PPAR $\alpha$ can depress the COX-1/2 induction in human. Activation of this PPAR may contribute to the anti-inflammatory activity of the pharmacological ligands that influence the development of atherosclerosis [170]. Resveratrol is able to activate PPAR $\alpha$ in vascular EC and its consumption (20 mg/kg, 3 days) reduces infarct volume by $36 \%$ at 24 hours after middle cerebral artery occlusion in mice [171]. In fact, resveratrol is a dual activator of PPAR $\alpha$ and PPAR $\gamma$ [171]. So, by this activation of PPARs, resveratrol could contribute to the lipid metabolism modulation and prevent the inflammatory activation of SMCs. Moreover, PPAR $\alpha$ shifts the human liver fatty-acid oxidation/glycerolipid esterification balance towards the catabolic route, thereby reducing TGs supply for VLDL synthesis and contributing to the antihypertriglyceridaemic action of resveratrol.

By attenuation of nuclear factors binding activity (e.g. NFאB, AP-1, GATA), resveratrol perturbs the control of the expression of various genes (e.g. ET-1, MCP-1, VCAM-1, ICAM1, SR-A, IL-1, IL-6) involved in atherosclerosis and inflammatory response [58, 65, 84, 172]. 


\section{Caloric}

Among the polyphenol with benefics properties, resveratrol, a phytoalexin of grapewine, can acts on the aging phenomena as well as caloric restriction which reduces atherosclerosis [173], inflammation [174] and deleters effects of aging [175]. 


\section{Conclusion}

In VSMCs, Ang II and TNF $\alpha$ were shown to induce these genes through the activation of $\mathrm{NF} \kappa \mathrm{B}$ in a ROS-dependent manner [176, 177]. 


\section{Acknowledgements}

This study was supported by the "Conseil Régional de Bourgogne” and the BIVB. Thanks to

D. Collin for graphic illustration. 


\section{References}

[1] Esterbauer, H., Dieber-Rotheneder, M., Striegl, G. and Waeg, G., Role of vitamin E in preventing the oxidation of low-density lipoprotein, Am J Clin Nutr. 1991, 53, 314S$321 \mathrm{~S}$.

[2] Rao, A.V., Lycopene, tomatoes, and the prevention of coronary heart disease, Exp Biol Med (Maywood). 2002, 227, 908-913.

[3] Frankel, E.N., Kanner, J., German, J.B., Parks, E. and Kinsella, J.E., Inhibition of oxidation of human low-density lipoprotein by phenolic substances in red wine, Lancet. 1993, 341, 454-457.

[4] Maron, D.J., Flavonoids for reduction of atherosclerotic risk, Curr Atheroscler Rep. 2004, 6, 73-78.

[5] Burzynski, S.R., Aging: gene silencing or gene activation?, Med Hypotheses. 2005, 64, 201-208.

[6] Wood, J.G., Rogina, B., Lavu, S., Howitz, K., Helfand, S.L., et al., Sirtuin activators mimic caloric restriction and delay ageing in metazoans, Nature. 2004, 430, 686-689.

[7] Steinberg, D., Parthasarathy, S., Carew, T.E., Khoo, J.C. and Witztum, J.L., Beyond cholesterol. Modifications of low-density lipoprotein that increase its atherogenicity, $N$ Engl J Med. 1989, 320, 915-924.

[8] Fukao, H., Ijiri, Y., Miura, M., Hashimoto, M., Yamashita, T., et al., Effect of transresveratrol on the thrombogenicity and atherogenicity in apolipoprotein E-deficient and low-density lipoprotein receptor-deficient mice, Blood Coagul Fibrinolysis. 2004, 15, 441-446.

[9] Pal, S., Ho, N., Santos, C., Dubois, P., Mamo, J., et al., Red wine polyphenolics increase LDL receptor expression and activity and suppress the secretion of ApoB100 from human HepG2 cells, J Nutr. 2003, 133, 700-706.

[10] Goldberg, D.M., Hahn, S.E. and Parkes, J.G., Beyond alcohol: beverage consumption and cardiovascular mortality, Clin Chim Acta. 1995, 237, 155-187.

[11] Miura, D., Miura, Y. and Yagasaki, K., Hypolipidemic action of dietary resveratrol, a phytoalexin in grapes and red wine, in hepatoma-bearing rats, Life Sci. 2003, 73, 13931400.

[12] Ratna, W.N. and Simonelli, J.A., The action of dietary phytochemicals quercetin, catechin, resveratrol and naringenin on estrogen-mediated gene expression, Life Sci. 2002, 70, 1577-1589.

[13] Stary, H.C., Chandler, A.B., Dinsmore, R.E., Fuster, V., Glagov, S., et al., A definition of advanced types of atherosclerotic lesions and a histological classification of atherosclerosis. A report from the Committee on Vascular Lesions of the Council on Arteriosclerosis, American Heart Association, Circulation. 1995, 92, 1355-1374.

[14] Witztum, J.L. and Steinberg, D., Role of oxidized low density lipoprotein in atherogenesis, J Clin Invest. 1991, 88, 1785-1792.

[15] Aviram, M., Modified forms of low density lipoprotein affect platelet aggregation in vitro, Thromb Res. 1989, 53, 561-567.

[16] Schuff-Werner, P., Claus, G., Armstrong, V.W., Kostering, H. and Seidel, D., Enhanced procoagulatory activity (PCA) of human monocytes/macrophages after in vitro stimulation with chemically modified LDL, Atherosclerosis. 1989, 78, 109-112.

[17] Drake, T.A., Hannani, K., Fei, H.H., Lavi, S. and Berliner, J.A., Minimally oxidized lowdensity lipoprotein induces tissue factor expression in cultured human endothelial cells, Am J Pathol. 1991, 138, 601-607.

[18] Frankel, E.N., Waterhouse, A.L. and Kinsella, J.E., Inhibition of human LDL oxidation by resveratrol, Lancet. 1993, 341, 1103-1104. 
[19] Fremont, L., Belguendouz, L. and Delpal, S., Antioxidant activity of resveratrol and alcohol-free wine polyphenols related to LDL oxidation and polyunsaturated fatty acids, Life Sci. 1999, 64, 2511-2521.

[20] Belguendouz, L., Fremont, L. and Linard, A., Resveratrol inhibits metal ion-dependent and independent peroxidation of porcine low-density lipoproteins, Biochem Pharmacol. 1997, 53, 1347-1355.

[21] Zou, J.G., Huang, Y.Z., Chen, Q., Wei, E.H., Hsieh, T.C., et al., Resveratrol inhibits copper ion-induced and azo compound-initiated oxidative modification of human low density lipoprotein, Biochem Mol Biol Int. 1999, 47, 1089-1096.

[22] Fauconneau, B., Waffo-Teguo, P., Huguet, F., Barrier, L., Decendit, A., et al., Comparative study of radical scavenger and antioxidant properties of phenolic compounds from Vitis vinifera cell cultures using in vitro tests, Life Sci. 1997, 61, 21032110.

[23] Stojanovic, S., Sprinz, H. and Brede, O., Efficiency and mechanism of the antioxidant action of trans-resveratrol and its analogues in the radical liposome oxidation, Arch Biochem Biophys. 2001, 391, 79-89.

[24] Meyer, J.W. and Schmitt, M.E., A central role for the endothelial NADPH oxidase in atherosclerosis, FEBS Lett. 2000, 472, 1-4.

[25] Carr, A.C., McCall, M.R. and Frei, B., Oxidation of LDL by myeloperoxidase and reactive nitrogen species: reaction pathways and antioxidant protection, Arterioscler Thromb Vasc Biol. 2000, 20, 1716-1723.

[26] Touyz, R.M., Chen, X., Tabet, F., Yao, G., He, G., et al., Expression of a functionally active gp91phox-containing neutrophil-type $\mathrm{NAD}(\mathrm{P}) \mathrm{H}$ oxidase in smooth muscle cells from human resistance arteries: regulation by angiotensin II, Circ Res. 2002, 90, 12051213.

[27] Orallo, F., Alvarez, E., Camina, M., Leiro, J.M., Gomez, E., et al., The possible implication of trans-Resveratrol in the cardioprotective effects of long-term moderate wine consumption, Mol Pharmacol. 2002, 61, 294-302.

[28] Leiro, J., Alvarez, E., Arranz, J.A., Laguna, R., Uriarte, E., et al., Effects of cisresveratrol on inflammatory murine macrophages: antioxidant activity and downregulation of inflammatory genes, J Leukoc Biol. 2004.

[29] Shigematsu, S., Ishida, S., Hara, M., Takahashi, N., Yoshimatsu, H., et al., Resveratrol, a red wine constituent polyphenol, prevents superoxide-dependent inflammatory responses induced by ischemia/reperfusion, platelet-activating factor, or oxidants, Free Radic Biol Med. 2003, 34, 810-817.

[30] Floreani, M., Napoli, E., Quintieri, L. and Palatini, P., Oral administration of transresveratrol to guinea pigs increases cardiac DT-diaphorase and catalase activities, and protects isolated atria from menadione toxicity, Life Sci. 2003, 72, 2741-2750.

[31] Jang, M. and Pezzuto, J.M., Cancer chemopreventive activity of resveratrol, Drugs Exp Clin Res. 1999, 25, 65-77.

[32] Jang, M. and Pezzuto, J.M., Effects of resveratrol on 12-O-tetradecanoylphorbol-13acetate-induced oxidative events and gene expression in mouse skin, Cancer Lett. 1998, 134, 81-89.

[33] Rankin, S.M., Parthasarathy, S. and Steinberg, D., Evidence for a dominant role of lipoxygenase(s) in the oxidation of LDL by mouse peritoneal macrophages, J Lipid Res. 1991, 32, 449-456.

[34] Parthasarathy, S., Wieland, E. and Steinberg, D., A role for endothelial cell lipoxygenase in the oxidative modification of low density lipoprotein, Proc Natl Acad Sci U S A. 1989, 86, 1046-1050. 
[35] Kimura, Y., Okuda, H. and Arichi, S., Effects of stilbenes on arachidonate metabolism in leukocytes, Biochim Biophys Acta. 1985, 834, 275-278.

[36] Bastianetto, S., Zheng, W.H. and Quirion, R., Neuroprotective abilities of resveratrol and other red wine constituents against nitric oxide-related toxicity in cultured hippocampal neurons, Br J Pharmacol. 2000, 131, 711-720.

[37] Pinto, M.C., Garcia-Barrado, J.A. and Macias, P., Resveratrol is a potent inhibitor of the dioxygenase activity of lipoxygenase, J Agric Food Chem. 1999, 47, 4842-4846.

[38] MacCarrone, M., Lorenzon, T., Guerrieri, P. and Agro, A.F., Resveratrol prevents apoptosis in K562 cells by inhibiting lipoxygenase and cyclooxygenase activity, Eur $J$ Biochem. 1999, 265, 27-34.

[39] Brito, P., Almeida, L.M. and Dinis, T.C., The interaction of resveratrol with ferrylmyoglobin and peroxynitrite; protection against LDL oxidation, Free Radic Res. 2002, 36, 621-631.

[40] Rotondo, S., Rajtar, G., Manarini, S., Celardo, A., Rotillo, D., et al., Effect of transresveratrol, a natural polyphenolic compound, on human polymorphonuclear leukocyte function, Br J Pharmacol. 1998, 123, 1691-1699.

[41] Blache, D., Rustan, I., Durand, P., Lesgards, G. and Loreau, N., Gas chromatographic analysis of resveratrol in plasma, lipoproteins and cells after in vitro incubations, $J$ Chromatogr B Biomed Sci Appl. 1997, 702, 103-110.

[42] Belguendouz, L., Fremont, L. and Gozzelino, M.T., Interaction of transresveratrol with plasma lipoproteins, Biochem Pharmacol. 1998, 55, 811-816.

[43] Jannin, B., Menzel, M., Berlot, J.P., Delmas, D., Lancon, A., et al., Transport of resveratrol, a cancer chemopreventive agent, to cellular targets: plasmatic protein binding and cell uptake, Biochem Pharmacol. 2004, 68, 1113-1118.

[44] Mietus-Snyder, M., Gowri, M.S. and Pitas, R.E., Class A scavenger receptor upregulation in smooth muscle cells by oxidized low density lipoprotein. Enhancement by calcium flux and concurrent cyclooxygenase-2 up-regulation, J Biol Chem. 2000, 275, 17661-17670.

[45] Gong, Q. and Pitas, R.E., Synergistic effects of growth factors on the regulation of smooth muscle cell scavenger receptor activity, J Biol Chem. 1995, 270, 21672-21678.

[46] Kaneuchi, M., Sasaki, M., Tanaka, Y., Yamamoto, R., Sakuragi, N., et al., Resveratrol suppresses growth of Ishikawa cells through down-regulation of EGF, Int J Oncol. 2003, 23, 1167-1172.

[47] Liu, Y. and Liu, G., Isorhapontigenin and resveratrol suppress oxLDL-induced proliferation and activation of ERK1/2 mitogen-activated protein kinases of bovine aortic smooth muscle cells, Biochem Pharmacol. 2004, 67, 777-785.

[48] Henriksen, T., Mahoney, E.M. and Steinberg, D., Enhanced macrophage degradation of low density lipoprotein previously incubated with cultured endothelial cells: recognition by receptors for acetylated low density lipoproteins, Proc Natl Acad Sci U S A. 1981, 78, 6499-6503.

[49] Parhami, F., Fang, Z.T., Fogelman, A.M., Andalibi, A., Territo, M.C., et al., Minimally modified low density lipoprotein-induced inflammatory responses in endothelial cells are mediated by cyclic adenosine monophosphate, J Clin Invest. 1993, 92, 471-478.

[50] Frostegard, J., Haegerstrand, A., Gidlund, M. and Nilsson, J., Biologically modified LDL increases the adhesive properties of endothelial cells, Atherosclerosis. 1991, 90, 119126.

[51] Zhong, M., Cheng, G.F., Wang, W.J., Guo, Y., Zhu, X.Y., et al., Inhibitory effect of resveratrol on interleukin 6 release by stimulated peritoneal macrophages of mice, Phytomedicine. 1999, 6, 79-84. 
[52] Feng, Y.H., Zou, J.P. and Li, X.Y., Effects of resveratrol and ethanol on production of pro-inflammatory factors from endotoxin activated murine macrophages, Acta Pharmacol Sin. 2002, 23, 1002-1006.

[53] Wang, M.J., Huang, H.M., Hsieh, S.J., Jeng, K.C. and Kuo, J.S., Resveratrol inhibits interleukin-6 production in cortical mixed glial cells under hypoxia/hypoglycemia followed by reoxygenation, J Neuroimmunol. 2001, 112, 28-34.

[54] Hansson, G.K., Cell-mediated immunity in atherosclerosis, Curr Opin Lipidol. 1997, 8, 301-311.

[55] Boscolo, P., del Signore, A., Sabbioni, E., Di Gioacchino, M., Di Giampaolo, L., et al., Effects of resveratrol on lymphocyte proliferation and cytokine release, Ann Clin Lab Sci. 2003, 33, 226-231.

[56] Gao, X., Xu, Y.X., Janakiraman, N., Chapman, R.A. and Gautam, S.C., Immunomodulatory activity of resveratrol: suppression of lymphocyte proliferation, development of cell-mediated cytotoxicity, and cytokine production, Biochem Pharmacol. 2001, 62, 1299-1308.

[57] Gao, X., Deeb, D., Media, J., Divine, G., Jiang, H., et al., Immunomodulatory activity of resveratrol: discrepant in vitro and in vivo immunological effects, Biochem Pharmacol. 2003, 66, 2427-2435.

[58] Holmes-McNary, M. and Baldwin, A.S., Jr., Chemopreventive properties of transresveratrol are associated with inhibition of activation of the IkappaB kinase, Cancer Res. 2000, 60, 3477-3483.

[59] Pendurthi, U.R., Williams, J.T. and Rao, L.V., Resveratrol, a polyphenolic compound found in wine, inhibits tissue factor expression in vascular cells : A possible mechanism for the cardiovascular benefits associated with moderate consumption of wine, Arterioscler Thromb Vasc Biol. 1999, 19, 419-426.

[60] Shen, F., Chen, S.J., Dong, X.J., Zhong, H., Li, Y.T., et al., Suppression of IL-8 gene transcription by resveratrol in phorbol ester treated human monocytic cells, J Asian Nat Prod Res. 2003, 5, 151-157.

[61] Ross, R., The pathogenesis of atherosclerosis: a perspective for the 1990s, Nature. 1993, 362, 801-809.

[62] Levitzki, A. and Gazit, A., Tyrosine kinase inhibition: an approach to drug development, Science. 1995, 267, 1782-1788.

[63] Rendu, F., Eldor, A., Grelac, F., Bachelot, C., Gazit, A., et al., Inhibition of platelet activation by tyrosine kinase inhibitors, Biochem Pharmacol. 1992, 44, 881-888.

[64] Bertelli, A.A., Baccalini, R., Battaglia, E., Falchi, M. and Ferrero, M.E., Resveratrol inhibits TNF alpha-induced endothelial cell activation, Therapie. 2001, 56, 613-616.

[65] Carluccio, M.A., Siculella, L., Ancora, M.A., Massaro, M., Scoditti, E., et al., Olive oil and red wine antioxidant polyphenols inhibit endothelial activation: antiatherogenic properties of Mediterranean diet phytochemicals, Arterioscler Thromb Vasc Biol. 2003, 23, 622-629.

[66] Ferrero, M.E., Bertelli, A.E., Fulgenzi, A., Pellegatta, F., Corsi, M.M., et al., Activity in vitro of resveratrol on granulocyte and monocyte adhesion to endothelium, Am J Clin Nutr. 1998, 68, 1208-1214.

[67] Ferrero, M.E., Bertelli, A.A., Pellegatta, F., Fulgenzi, A., Corsi, M.M., et al., Phytoalexin resveratrol (3-4'-5-trihydroxystilbene) modulates granulocyte and monocyte endothelial adhesion, Transplant Proc. 1998, 30, 4191-4193.

[68] Ahn, K.S., Kim, J.H., Oh, S.R., Ryu, S.Y. and Lee, H.K., Inhibitory activity of stilbenes from medicinal plants on the expression of cell adhesion molecules on THP1 cells, Planta Med. 2000, 66, 641-644. 
[69] Bertelli, A.A., Giovannini, L., Stradi, R., Bertelli, A. and Tillement, J.P., Plasma, urine and tissue levels of trans- and cis-resveratrol (3,4',5-trihydroxystilbene) after short-term or prolonged administration of red wine to rats, Int J Tissue React. 1996, 18, 67-71.

[70] Asensi, M., Medina, I., Ortega, A., Carretero, J., Bano, M.C., et al., Inhibition of cancer growth by resveratrol is related to its low bioavailability, Free Radic Biol Med. 2002, 33, 387-398.

[71] Harlan, J.M., Neutrophil-mediated vascular injury, Acta Med Scand Suppl. 1987, 715, 123-129.

[72] Totani, L., Piccoli, A., Pellegrini, G., Di Santo, A. and Lorenzet, R., Polymorphonuclear leukocytes enhance release of growth factors by cultured endothelial cells, Arterioscler Thromb. 1994, 14, 125-132.

[73] Ross, R., Atherosclerosis--an inflammatory disease, $N$ Engl J Med. 1999, 340, 115-126.

[74] Araim, O., Ballantyne, J., Waterhouse, A.L. and Sumpio, B.E., Inhibition of vascular smooth muscle cell proliferation with red wine and red wine polyphenols, $J$ Vasc Surg. 2002, 35, 1226-1232.

[75] Mnjoyan, Z.H. and Fujise, K., Profound negative regulatory effects by resveratrol on vascular smooth muscle cells: a role of p53-p21(WAF1/CIP1) pathway, Biochem Biophys Res Commun. 2003, 311, 546-552.

[76] Zou, J., Huang, Y., Chen, Q., Wang, N., Cao, K., et al., Suppression of mitogenesis and regulation of cell cycle traverse by resveratrol in cultured smooth muscle cells, Int $J$ Oncol. 1999, 15, 647-651.

[77] Haider, U.G., Sorescu, D., Griendling, K.K., Vollmar, A.M. and Dirsch, V.M., Resveratrol increases serine15-phosphorylated but transcriptionally impaired p53 and induces a reversible DNA replication block in serum-activated vascular smooth muscle cells, Mol Pharmacol. 2003, 63, 925-932.

[78] Mizutani, K., Ikeda, K. and Yamori, Y., Resveratrol inhibits AGEs-induced proliferation and collagen synthesis activity in vascular smooth muscle cells from stroke-prone spontaneously hypertensive rats, Biochem Biophys Res Commun. 2000, 274, 61-67.

[79] Davi, G., Ciabattoni, G., Consoli, A., Mezzetti, A., Falco, A., et al., In vivo formation of 8-iso-prostaglandin f2alpha and platelet activation in diabetes mellitus: effects of improved metabolic control and vitamin E supplementation, Circulation. 1999, 99, 224229.

[80] Mizutani, K., Ikeda, K., Nishikata, T. and Yamori, Y., Phytoestrogens attenuate oxidative DNA damage in vascular smooth muscle cells from stroke-prone spontaneously hypertensive rats, J Hypertens. 2000, 18, 1833-1840.

[81] Hsieh, T.C., Juan, G., Darzynkiewicz, Z. and Wu, J.M., Resveratrol increases nitric oxide synthase, induces accumulation of p53 and p21(WAF1/CIP1), and suppresses cultured bovine pulmonary artery endothelial cell proliferation by perturbing progression through S and G2, Cancer Res. 1999, 59, 2596-2601.

[82] Bruder, J.L., Hsieh, T., Lerea, K.M., Olson, S.C. and Wu, J.M., Induced cytoskeletal changes in bovine pulmonary artery endothelial cells by resveratrol and the accompanying modified responses to arterial shear stress, BMC Cell Biol. 2001, 2, 1.

[83] Ruef, J., Moser, M., Kubler, W. and Bode, C., Induction of endothelin-1 expression by oxidative stress in vascular smooth muscle cells, Cardiovasc Pathol. 2001, 10, 311-315.

[84] Liu, J.C., Chen, J.J., Chan, P., Cheng, C.F. and Cheng, T.H., Inhibition of cyclic straininduced endothelin-1 gene expression by resveratrol, Hypertension. 2003, 42, 11981205.

[85] Yanagisawa, M., Kurihara, H., Kimura, S., Tomobe, Y., Kobayashi, M., et al., A novel potent vasoconstrictor peptide produced by vascular endothelial cells, Nature. 1988, 332, 411-415. 
[86] Haider, U.G., Sorescu, D., Griendling, K.K., Vollmar, A.M. and Dirsch, V.M., Resveratrol suppresses angiotensin II-induced Akt/protein kinase B and p70 S6 kinase phosphorylation and subsequent hypertrophy in rat aortic smooth muscle cells, $\mathrm{Mol}$ Pharmacol. 2002, 62, 772-777.

[87] Olson, E.R., Naugle, J.E., Zhang, X., Bomser, J.A. and Meszaros, J.G., Inhibition of cardiac fibroblast proliferation and myofibroblast differentiation by resveratrol, $A m J$ Physiol Heart Circ Physiol. 2004.

[88] Cesari, M., Pavan, E., Sacchetto, A. and Rossi, G.P., Endothelin-1: a scientist's curiosity, or a real player in ischemic heart disease?, Am Heart J. 1996, 132, 1236-1243.

[89] Chen, C.K. and Pace-Asciak, C.R., Vasorelaxing activity of resveratrol and quercetin in isolated rat aorta, Gen Pharmacol. 1996, 27, 363-366.

[90] Fitzpatrick, D.F., Hirschfield, S.L. and Coffey, R.G., Endothelium-dependent vasorelaxing activity of wine and other grape products, Am J Physiol. 1993, 265, H774778.

[91] Andriambeloson, E., Kleschyov, A.L., Muller, B., Beretz, A., Stoclet, J.C., et al., Nitric oxide production and endothelium-dependent vasorelaxation induced by wine polyphenols in rat aorta, Br J Pharmacol. 1997, 120, 1053-1058.

[92] Cishek, M.B., Galloway, M.T., Karim, M., German, J.B. and Kappagoda, C.T., Effect of red wine on endothelium-dependent relaxation in rabbits, Clin Sci (Lond). 1997, 93, 507-511.

[93] Flesch, M., Schwarz, A. and Bohm, M., Effects of red and white wine on endotheliumdependent vasorelaxation of rat aorta and human coronary arteries, Am J Physiol. 1998, 275, H1183-1190.

[94] Wallerath, T., Deckert, G., Ternes, T., Anderson, H., Li, H., et al., Resveratrol, a polyphenolic phytoalexin present in red wine, enhances expression and activity of endothelial nitric oxide synthase, Circulation. 2002, 106, 1652-1658.

[95] Li, H.F., Chen, S.A. and Wu, S.N., Evidence for the stimulatory effect of resveratrol on $\mathrm{Ca}(2+)$-activated $\mathrm{K}+$ current in vascular endothelial cells, Cardiovasc Res. 2000, 45, 1035-1045.

[96] El-Mowafy, A.M., Resveratrol activates membrane-bound guanylyl cyclase in coronary arterial smooth muscle: a novel signaling mechanism in support of coronary protection, Biochem Biophys Res Commun. 2002, 291, 1218-1224.

[97] Chen, Z.J., Che, D. and Chang, C.H., Antioxidants, vitamin C and dithiothreitol, activate membrane-bound guanylate cyclase in PC12 cells, J Pharm Pharmacol. 2001, 53, 243247.

[98] Lucas, K.A., Pitari, G.M., Kazerounian, S., Ruiz-Stewart, I., Park, J., et al., Guanylyl cyclases and signaling by cyclic GMP, Pharmacol Rev. 2000, 52, 375-414.

[99] Granados-Soto, V., Arguelles, C.F. and Ortiz, M.I., The peripheral antinociceptive effect of resveratrol is associated with activation of potassium channels, Neuropharmacology. 2002, 43, 917-923.

[100] Wu, S.N., Large-conductance Ca2+- activated K+ channels:physiological role and pharmacology, Curr Med Chem. 2003, 10, 649-661.

[101] Inoue, M., Itoh, H., Ueda, M., Naruko, T., Kojima, A., et al., Vascular endothelial growth factor (VEGF) expression in human coronary atherosclerotic lesions: possible pathophysiological significance of VEGF in progression of atherosclerosis, Circulation. 1998, 98, 2108-2116.

[102] Lin, M.T., Yen, M.L., Lin, C.Y. and Kuo, M.L., Inhibition of vascular endothelial growth factor-induced angiogenesis by resveratrol through interruption of Src-dependent vascular endothelial cadherin tyrosine phosphorylation, Mol Pharmacol. 2003, 64, 1029-1036. 
[103] Arbiser, J.L., Petros, J., Klafter, R., Govindajaran, B., McLaughlin, E.R., et al., Reactive oxygen generated by Nox1 triggers the angiogenic switch, Proc Natl Acad Sci U S A. 2002, 99, 715-720.

[104] Ushio-Fukai, M., Tang, Y., Fukai, T., Dikalov, S.I., Ma, Y., et al., Novel role of gp91(phox)-containing NAD(P)H oxidase in vascular endothelial growth factor-induced signaling and angiogenesis, Circ Res. 2002, 91, 1160-1167.

[105] Brakenhielm, E., Cao, R. and Cao, Y., Suppression of angiogenesis, tumor growth, and wound healing by resveratrol, a natural compound in red wine and grapes, Faseb J. 2001, 15, 1798-1800.

[106] Pace-Asciak, C.R., Rounova, O., Hahn, S.E., Diamandis, E.P. and Goldberg, D.M., Wines and grape juices as modulators of platelet aggregation in healthy human subjects, Clin Chim Acta. 1996, 246, 163-182.

[107] Olas, B., Wachowicz, B., Stochmal, A. and Oleszek, W., Anti-platelet effects of different phenolic compounds from Yucca schidigera Roezl. bark, Platelets. 2002, 13, 167-173.

[108] Bertelli, A.A., Giovannini, L., Giannessi, D., Migliori, M., Bernini, W., et al., Antiplatelet activity of synthetic and natural resveratrol in red wine, Int J Tissue React. 1995, 17, 1-3.

[109] Wang, Z., Huang, Y., Zou, J., Cao, K., Xu, Y., et al., Effects of red wine and wine polyphenol resveratrol on platelet aggregation in vivo and in vitro, Int J Mol Med. 2002, 9, 77-79.

[110] Kaneider, N.C., Mosheimer, B., Reinisch, N., Patsch, J.R. and Wiedermann, C.J., Inhibition of thrombin-induced signaling by resveratrol and quercetin: effects on adenosine nucleotide metabolism in endothelial cells and platelet-neutrophil interactions, Thromb Res. 2004, 114, 185-194.

[111] Olas, B., Zbikowska, H.M., Wachowicz, B., Krajewski, T., Buczynski, A., et al., Inhibitory effect of resveratrol on free radical generation in blood platelets, Acta Biochim Pol. 1999, 46, 961-966.

[112] Olas, B., Wachowicz, B., Saluk-Juszczak, J., Zielinski, T., Kaca, W., et al., Antioxidant activity of resveratrol in endotoxin-stimulated blood platelets, Cell Biol Toxicol. 2001, 17, 117-125.

[113] Fragopoulou, E., Nomikos, T., Antonopoulou, S., Mitsopoulou, C.A. and Demopoulos, C.A., Separation of biologically active lipids from red wine, J Agric Food Chem. 2000, 48, 1234-1238.

[114] Johnson, J.L. and Maddipati, K.R., Paradoxical effects of resveratrol on the two prostaglandin H synthases, Prostaglandins Other Lipid Mediat. 1998, 56, 131-143.

[115] Pinto Mdel, C., Garcia-Barrado, J.A. and Macias, P., Oxidation of resveratrol catalyzed by soybean lipoxygenase, J Agric Food Chem. 2003, 51, 1653-1657.

[116] Kimura, Y., Okuda, H. and Kubo, M., Effects of stilbenes isolated from medicinal plants on arachidonate metabolism and degranulation in human polymorphonuclear leukocytes, J Ethnopharmacol. 1995, 45, 131-139.

[117] Pace-Asciak, C.R., Hepoxilins, Gen Pharmacol. 1993, 24, 805-810.

[118] Pace-Asciak, C.R., Hahn, S., Diamandis, E.P., Soleas, G. and Goldberg, D.M., The red wine phenolics trans-resveratrol and quercetin block human platelet aggregation and eicosanoid synthesis: implications for protection against coronary heart disease, Clin Chim Acta. 1995, 235, 207-219.

[119] Eling, T.E., Thompson, D.C., Foureman, G.L., Curtis, J.F. and Hughes, M.F., Prostaglandin H synthase and xenobiotic oxidation, Annu Rev Pharmacol Toxicol. 1990, 30, 1-45. 
[120] Kulmacz, R.J. and Wang, L.H., Comparison of hydroperoxide initiator requirements for the cyclooxygenase activities of prostaglandin H synthase-1 and -2, J Biol Chem. 1995, 270, 24019-24023.

[121] Maccarrone, M., Putti, S. and Finazzi Agro, A., Nitric oxide donors activate the cyclooxygenase and peroxidase activities of prostaglandin H synthase, FEBS Lett. 1997, 410, 470-476.

[122] Martinez, J. and Moreno, J.J., Effect of resveratrol, a natural polyphenolic compound, on reactive oxygen species and prostaglandin production, Biochem Pharmacol. 2000, 59, 865-870.

[123] Moreno, J.J., Resveratrol modulates arachidonic acid release, prostaglandin synthesis, and $3 T 6$ fibroblast growth, J Pharmacol Exp Ther. 2000, 294, 333-338.

[124] Dobrydneva, Y., Williams, R.L. and Blackmore, P.F., trans-Resveratrol inhibits calcium influx in thrombin-stimulated human platelets, Br J Pharmacol. 1999, 128, 149-157.

[125] Dobrydneva, Y., Williams, R.L., Morris, G.Z. and Blackmore, P.F., Dietary phytoestrogens and their synthetic structural analogues as calcium channel blockers in human platelets, J Cardiovasc Pharmacol. 2002, 40, 399-410.

[126] Dobrydneva, Y., Williams, R.L., Katzenellenbogen, J.A., Ratz, P.H. and Blackmore, P.F., Diethylstilbestrol and tetrahydrochrysenes are calcium channel blockers in human platelets: relationship to the stilbene pharmacophore, Thromb Res. 2003, 110, 23-31.

[127] Slater, S.J., Seiz, J.L., Cook, A.C., Stagliano, B.A. and Buzas, C.J., Inhibition of protein kinase C by resveratrol, Biochim Biophys Acta. 2003, 1637, 59-69.

[128] Escargueil-Blanc, I., Meilhac, O., Pieraggi, M.T., Arnal, J.F., Salvayre, R., et al., Oxidized LDLs induce massive apoptosis of cultured human endothelial cells through a calcium-dependent pathway. Prevention by aurintricarboxylic acid, Arterioscler Thromb Vasc Biol. 1997, 17, 331-339.

[129] Bertelli, A.A., Giovannini, L., Bernini, W., Migliori, M., Fregoni, M., et al., Antiplatelet activity of cis-resveratrol, Drugs Exp Clin Res. 1996, 22, 61-63.

[130] Olas, B., Wachowicz, B., Szewczuk, J., Saluk-Juszczak, J. and Kaca, W., The effect of resveratrol on the platelet secretory process induced by endotoxin and thrombin, Microbios. 2001, 105, 7-13.

[131] Godichaud, S., Krisa, S., Couronne, B., Dubuisson, L., Merillon, J.M., et al., Deactivation of cultured human liver myofibroblasts by trans-resveratrol, a grapevinederived polyphenol, Hepatology. 2000, 31, 922-931.

[132] Kirk, R.I., Deitch, J.A., Wu, J.M. and Lerea, K.M., Resveratrol decreases early signaling events in washed platelets but has little effect on platalet in whole food, Blood Cells Mol Dis. 2000, 26, 144-150.

[133] Zbikowska, H.M. and Olas, B., Antioxidants with carcinostatic activity (resveratrol, vitamin E and selenium) in modulation of blood platelet adhesion, J Physiol Pharmacol. 2000, 51, 513-520.

[134] Olas, B., Wachowicz, B., Saluk-Juszczak, J. and Zielinski, T., Effect of resveratrol, a natural polyphenolic compound, on platelet activation induced by endotoxin or thrombin, Thromb Res. 2002, 107, 141-145.

[135] Abou-Agag, L.H., Aikens, M.L., Tabengwa, E.M., Benza, R.L., Shows, S.R., et al., Polyphyenolics increase t-PA and u-PA gene transcription in cultured human endothelial cells, Alcohol Clin Exp Res. 2001, 25, 155-162.

[136] Semeraro, N. and Colucci, M., Tissue factor in health and disease, Thromb Haemost. 1997, 78, 759-764.

[137] Pendurthi, U.R., Meng, F., Mackman, N. and Rao, L.V., Mechanism of resveratrolmediated suppression of tissue factor gene expression, Thromb Haemost. 2002, 87, 155 162. 
[138] Di Santo, A., Mezzetti, A., Napoleone, E., Di Tommaso, R., Donati, M.B., et al., Resveratrol and quercetin down-regulate tissue factor expression by human stimulated vascular cells, $J$ Thromb Haemost. 2003, 1, 1089-1095.

[139] Garcia-Garcia, J., Micol, V., de Godos, A. and Gomez-Fernandez, J.C., The cancer chemopreventive agent resveratrol is incorporated into model membranes and inhibits protein kinase C alpha activity, Arch Biochem Biophys. 1999, 372, 382-388.

[140] Jayatilake, G.S., Jayasuriya, H., Lee, E.S., Koonchanok, N.M., Geahlen, R.L., et al., Kinase inhibitors from Polygonum cuspidatum, J Nat Prod. 1993, 56, 1805-1810.

[141] Stewart, J.R., Ward, N.E., Ioannides, C.G. and O'Brian, C.A., Resveratrol preferentially inhibits protein kinase C-catalyzed phosphorylation of a cofactor-independent, argininerich protein substrate by a novel mechanism, Biochemistry. 1999, 38, 13244-13251.

[142] El-Mowafy, A.M. and White, R.E., Resveratrol inhibits MAPK activity and nuclear translocation in coronary artery smooth muscle: reversal of endothelin-1 stimulatory effects, FEBS Lett. 1999, 451, 63-67.

[143] Thurberg, B.L. and Collins, T., The nuclear factor-kappa B/inhibitor of kappa B autoregulatory system and atherosclerosis, Curr Opin Lipidol. 1998, 9, 387-396.

[144] Draczynska-Lusiak, B., Chen, Y.M. and Sun, A.Y., Oxidized lipoproteins activate NFkappaB binding activity and apoptosis in PC12 cells, Neuroreport. 1998, 9, 527-532.

[145] Adhami, V.M., Afaq, F. and Ahmad, N., Suppression of ultraviolet B exposuremediated activation of NF-kappaB in normal human keratinocytes by resveratrol, Neoplasia. 2003, 5, 74-82.

[146] Manna, S.K., Mukhopadhyay, A. and Aggarwal, B.B., Resveratrol suppresses TNFinduced activation of nuclear transcription factors NF-kappa B, activator protein-1, and apoptosis: potential role of reactive oxygen intermediates and lipid peroxidation, $J$ Immunol. 2000, 164, 6509-6519.

[147] Storz, P., Doppler, H. and Toker, A., Activation loop phosphorylation controls protein kinase D-dependent activation of nuclear factor kappaB, Mol Pharmacol. 2004, 66, 870879.

[148] Pellegatta, F., Bertelli, A.A., Staels, B., Duhem, C., Fulgenzi, A., et al., Different shortand long-term effects of resveratrol on nuclear factor-kappaB phosphorylation and nuclear appearance in human endothelial cells, Am J Clin Nutr. 2003, 77, 1220-1228.

[149] Donnelly, L.E., Newton, R., Kennedy, G.E., Fenwick, P.S., Leung, R.H., et al., Antiinflammatory Effects of Resveratrol in Lung Epithelial Cells: Molecular Mechanisms, Am J Physiol Lung Cell Mol Physiol. 2004.

[150] Subbaramaiah, K., Chung, W.J., Michaluart, P., Telang, N., Tanabe, T., et al., Resveratrol inhibits cyclooxygenase-2 transcription and activity in phorbol ester-treated human mammary epithelial cells, J Biol Chem. 1998, 273, 21875-21882.

[151] Subbaramaiah, K., Michaluart, P., Chung, W.J., Tanabe, T., Telang, N., et al., Resveratrol inhibits cyclooxygenase-2 transcription in human mammary epithelial cells, Ann N Y Acad Sci. 1999, 889, 214-223.

[152] Yu, R., Hebbar, V., Kim, D.W., Mandlekar, S., Pezzuto, J.M., et al., Resveratrol inhibits phorbol ester and UV-induced activator protein 1 activation by interfering with mitogenactivated protein kinase pathways, Mol Pharmacol. 2001, 60, 217-224.

[153] Karin, M. and Delhase, M., JNK or IKK, AP-1 or NF-kappaB, which are the targets for MEK kinase 1 action?, Proc Natl Acad Sci U S A. 1998, 95, 9067-9069.

[154] Lee, F.S., Hagler, J., Chen, Z.J. and Maniatis, T., Activation of the IkappaB alpha kinase complex by MEKK1, a kinase of the JNK pathway, Cell. 1997, 88, 213-222.

[155] Yang, S. and Meyskens, F., Resveratrol induces AP-1 inhibition, altered AP-1 composition and increased expression of specific jun and fos family proteins in human Melanoma cells, Pigment Cell Res. 2004, 17, 445. 
[156] Xie, Q.W., Kashiwabara, Y. and Nathan, C., Role of transcription factor NF-kappa B/Rel in induction of nitric oxide synthase, J Biol Chem. 1994, 269, 4705-4708.

[157] Chan, M.M., Mattiacci, J.A., Hwang, H.S., Shah, A. and Fong, D., Synergy between ethanol and grape polyphenols, quercetin, and resveratrol, in the inhibition of the inducible nitric oxide synthase pathway, Biochem Pharmacol. 2000, 60, 1539-1548.

[158] Kawada, N., Seki, S., Inoue, M. and Kuroki, T., Effect of antioxidants, resveratrol, quercetin, and $\mathrm{N}$-acetylcysteine, on the functions of cultured rat hepatic stellate cells and Kupffer cells, Hepatology. 1998, 27, 1265-1274.

[159] Kim, H.K., Cheon, B.S., Kim, Y.H., Kim, S.Y. and Kim, H.P., Effects of naturally occurring flavonoids on nitric oxide production in the macrophage cell line RAW 264.7 and their structure-activity relationships, Biochem Pharmacol. 1999, 58, 759-765.

[160] Soliman, K.F. and Mazzio, E.A., In vitro attenuation of nitric oxide production in C6 astrocyte cell culture by various dietary compounds, Proc Soc Exp Biol Med. 1998, 218, 390-397.

[161] Tsai, S.H., Lin-Shiau, S.Y. and Lin, J.K., Suppression of nitric oxide synthase and the down-regulation of the activation of NFkappaB in macrophages by resveratrol, $\mathrm{Br} \mathrm{J}$ Pharmacol. 1999, 126, 673-680.

[162] Wadsworth, T.L. and Koop, D.R., Effects of the wine polyphenolics quercetin and resveratrol on pro-inflammatory cytokine expression in RAW 264.7 macrophages, Biochem Pharmacol. 1999, 57, 941-949.

[163] Schonbeck, U., Sukhova, G.K., Graber, P., Coulter, S. and Libby, P., Augmented expression of cyclooxygenase-2 in human atherosclerotic lesions, Am J Pathol. 1999, 155, 1281-1291.

[164] Baker, C.S., Hall, R.J., Evans, T.J., Pomerance, A., Maclouf, J., et al., Cyclooxygenase2 is widely expressed in atherosclerotic lesions affecting native and transplanted human coronary arteries and colocalizes with inducible nitric oxide synthase and nitrotyrosine particularly in macrophages, Arterioscler Thromb Vasc Biol. 1999, 19, 646-655.

[165] Yamamoto, K., Arakawa, T., Ueda, N. and Yamamoto, S., Transcriptional roles of nuclear factor kappa B and nuclear factor-interleukin-6 in the tumor necrosis factor alpha-dependent induction of cyclooxygenase-2 in MC3T3-E1 cells, J Biol Chem. 1995, 270, 31315-31320.

[166] Aggarwal, B.B., Bhardwaj, A., Aggarwal, R.S., Seeram, N.P., Shishodia, S., et al., Role of resveratrol in prevention and therapy of cancer: preclinical and clinical studies, Anticancer Res. 2004, 24, 2783-2840.

[167] Takada, Y., Bhardwaj, A., Potdar, P. and Aggarwal, B.B., Nonsteroidal antiinflammatory agents differ in their ability to suppress NF-kappaB activation, inhibition of expression of cyclooxygenase-2 and cyclin D1, and abrogation of tumor cell proliferation, Oncogene. 2004.

[168] Murias, M., Handler, N., Erker, T., Pleban, K., Ecker, G., et al., Resveratrol analogues as selective cyclooxygenase-2 inhibitors: synthesis and structure-activity relationship, Bioorg Med Chem. 2004, 12, 5571-5578.

[169] Staels, B., Koenig, W., Habib, A., Merval, R., Lebret, M., et al., Activation of human aortic smooth-muscle cells is inhibited by PPARalpha but not by PPARgamma activators, Nature. 1998, 393, 790-793.

[170] Fruchart, J.C., Duriez, P. and Staels, B., Peroxisome proliferator-activated receptoralpha activators regulate genes governing lipoprotein metabolism, vascular inflammation and atherosclerosis, Curr Opin Lipidol. 1999, 10, 245-257.

[171] Inoue, H., Jiang, X.F., Katayama, T., Osada, S., Umesono, K., et al., Brain protection by resveratrol and fenofibrate against stroke requires peroxisome proliferator-activated receptor alpha in mice, Neurosci Lett. 2003, 352, 203-206. 
[172] Collins, T. and Cybulsky, M.I., NF-kappaB: pivotal mediator or innocent bystander in atherogenesis?, J Clin Invest. 2001, 107, 255-264.

[173] Rajala, M.W. and Scherer, P.E., Minireview: The adipocyte--at the crossroads of energy homeostasis, inflammation, and atherosclerosis, Endocrinology. 2003, 144, 3765-3773.

[174] Chung, H.Y., Kim, H.J., Kim, K.W., Choi, J.S. and Yu, B.P., Molecular inflammation hypothesis of aging based on the anti-aging mechanism of calorie restriction, Microsc Res Tech. 2002, 59, 264-272.

[175] Kim, H.J., Jung, K.J., Yu, B.P., Cho, C.G., Choi, J.S., et al., Modulation of redoxsensitive transcription factors by calorie restriction during aging, Mech Ageing Dev. 2002, 123, 1589-1595.

[176] Chen, X.L., Tummala, P.E., Olbrych, M.T., Alexander, R.W. and Medford, R.M., Angiotensin II induces monocyte chemoattractant protein-1 gene expression in rat vascular smooth muscle cells, Circ Res. 1998, 83, 952-959.

[177] Han, Y., Runge, M.S. and Brasier, A.R., Angiotensin II induces interleukin-6 transcription in vascular smooth muscle cells through pleiotropic activation of nuclear factor-kappa B transcription factors, Circ Res. 1999, 84, 695-703. 


\section{Legends of figures}

Figure 1: Chemical structure of resveratrol (3,5,4'-trihydroxystilben in classical nomenclature).

Figure 2: Resveratrol effects on initial events of atherosclerosis. Resveratrol (R) prevents the initial events by scavenging the ROS (*), by inhibition of the enzymatic systems producing ROS (NADPH oxidase, Hypoxanthine / xanthine oxidase (HX/XO), cyclooxygenase (COX)), by dowregulation of scavenger receptor (SR-A) stimulated by several factors, by induction of e NOS involving a vasorelaxation.

Figure 3: Resveratrol effects on chemokine production. Resveratrol (R) decreases significantly the expression of ICAM-1 and VCAM-1 induced on endothelial cells by TNF- $\alpha$ or lipopolysaccharide LPS, as well as neutrophile and monocyte endothelial adhesion. Resveratrol can also inhibits iNOS as well as MPO secreted from macrophages and so reduces the endothelial activation- and inflammation-mediated by oxLDLs. The polyphenol can reduce the apoptosis of ECs induced by TNF $\alpha$ and AngII.

Figure 4: Resveratrol effects on advanced atherosclerotic lesion formation. Resveratrol (R) blocks the cytokine production and reduces the SMC proliferation and migration. Furthermore, resveratrol inhibits paletelet aggregation as well as pro-aggregants/ proinflammatory agents (eicosanoids, leukotrienes) and subsequently inhibits the formation of a thrombus.

Figure 5: Resveratrol effects on signaling pathways. Resveratrol inhibits VEGF-induced angiogenesis by disruption of ROS-dependent Src kinase activation. By this action on Src and MAPk cascade, resveratrol inhibits angiogenesis and the translocation of nuclear factors into the nucleus from the cytoplasm. Moreover, resveratrol exogenous oxidants (oxLDLs, ROS), calcium flux and synthesis of pro-inflammatory compounds. The polyphenol can also inhibit stimuli involved in the activation of NFאB pathway such as PKC $\alpha$ signal transduction, IкB phosphorylation, IKK activity, p50/p65 nuclear translocation. These effects on the signaling pathways lead to a down-regulation of many gene transcription (COX-2, iNOS, VACM, SR-A,...) involved in atherosclerotic process and inflammation. 


\section{Figures}

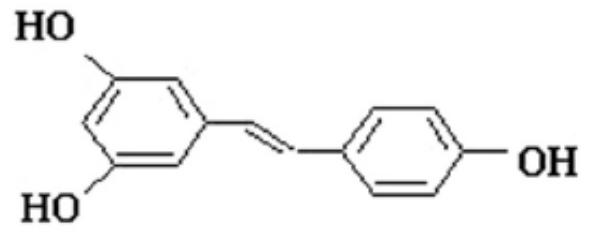

Figure 1. Chemical structure of resveratrol (3,5,4'-trihydroxystilbene in classical nomenclature).

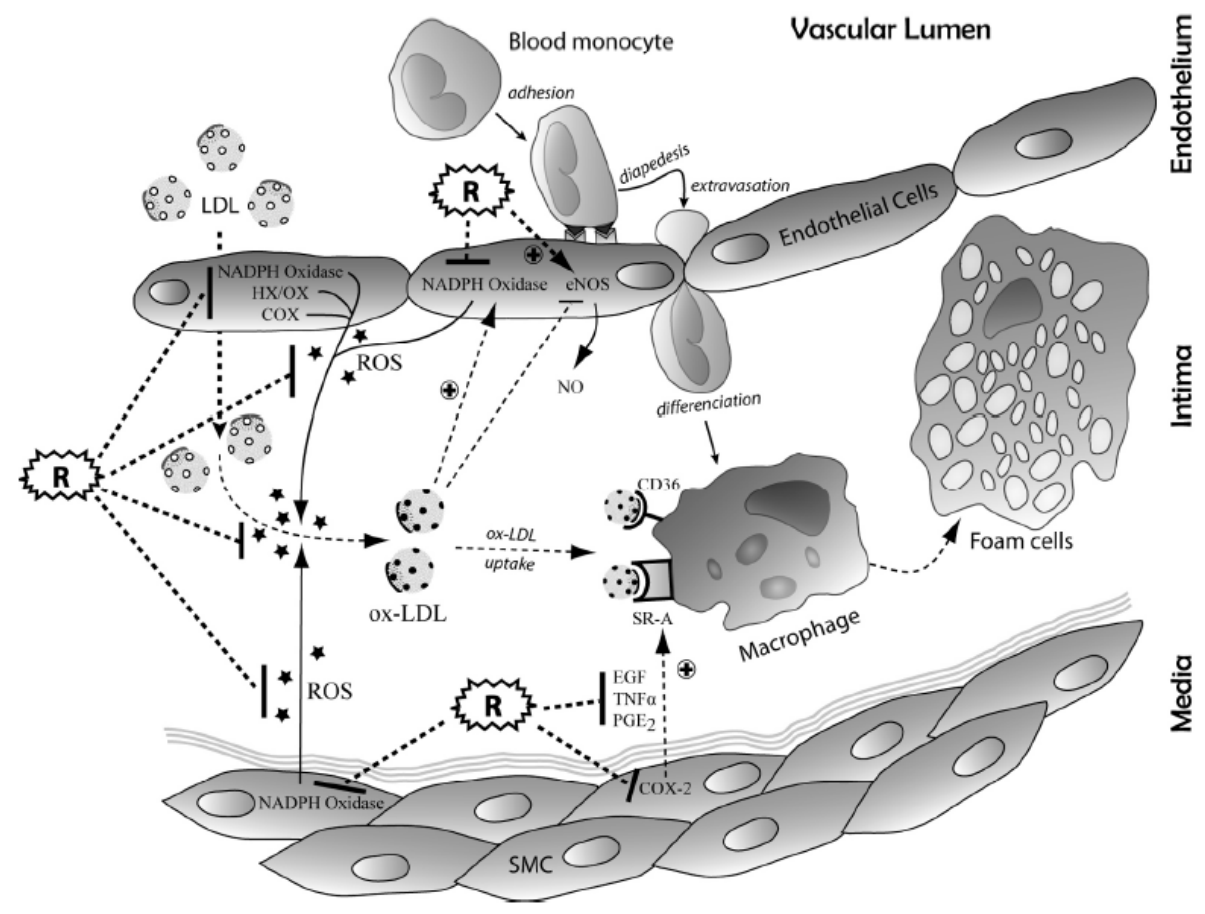

Figure 2. Resveratrol effects on initial events of atherosclerosis. Resveratrol $(R)$ prevents the initial events by scavenging the ROS $(\star)$, by inhibition of the enzymatic systems producing ROS (NADPH oxidase, hypoxanthine/xanthine oxidase (HX/XO), cyclooxygenase $(\mathrm{COX})$ ), by downregulation of scavenger receptor (SR-A) stimulated by several factors, by induction of eNOS involving a vasorelaxation. 


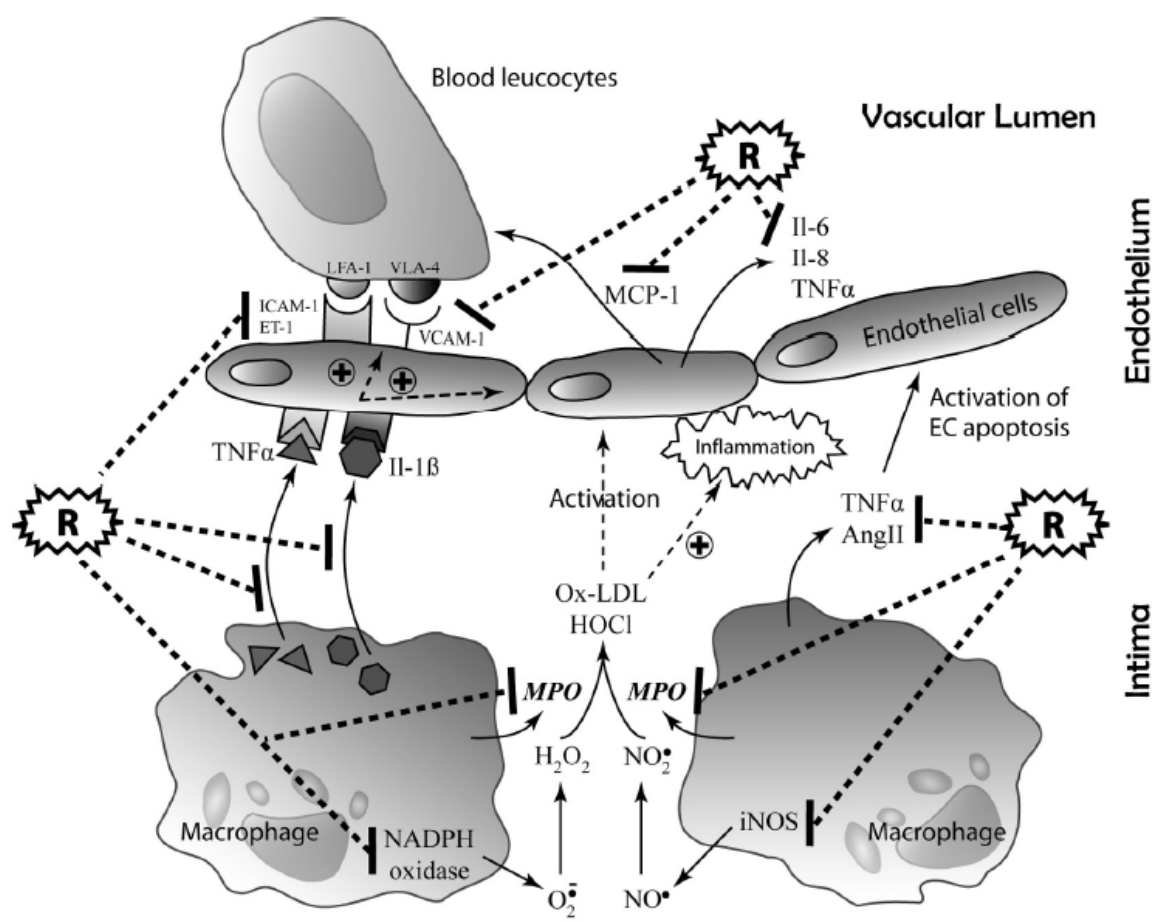

Figure 3. Resveratrol effects on chemokine production. Resveratrol $(R)$ decreases significantly the expression of ICAM-1 and VCAM-1 induced on endothelial cells by TNF- $\alpha$ or lipopolysaccharide LPS, as well as neutrophile and monocyte endothelial adhesion. Resveratrol can also inhibit iNOS as well as MPO secreted from macrophages and so reduces the endothelial activation and inflammation mediated by oxLDLs. The polyphenol can reduce the apoptosis of ECs induced by TNF $\alpha$ and Angll.

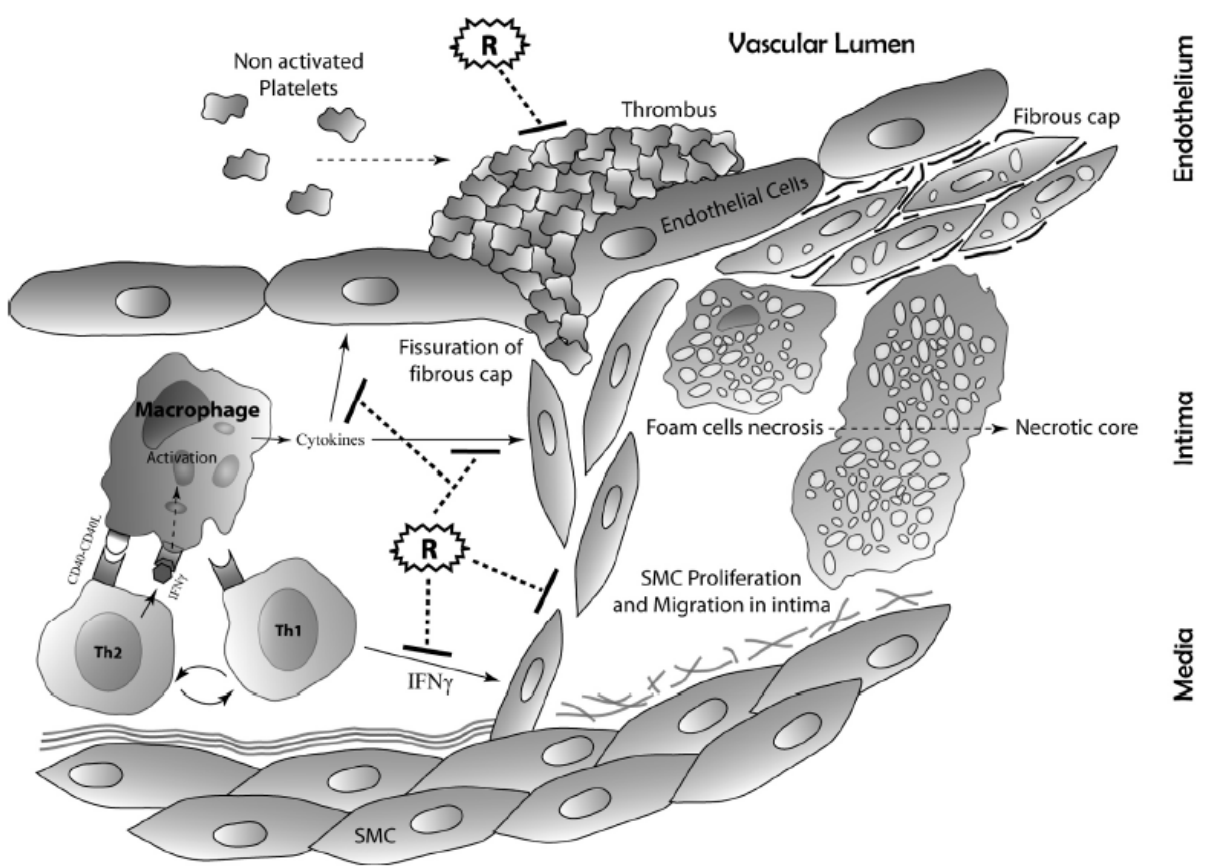

Figure 4. Resveratrol effects on advanced atherosclerotic lesion formation. Resveratrol (R) blocks the cytokine production and reduces the SMC proliferation and migration. Furthermore, resveratrol inhibits paletelet aggregation as well as pro-aggregants/proinflammatory agents (eicosanoids, leukotrienes) and subsequently inhibits the formation of a thrombus. 


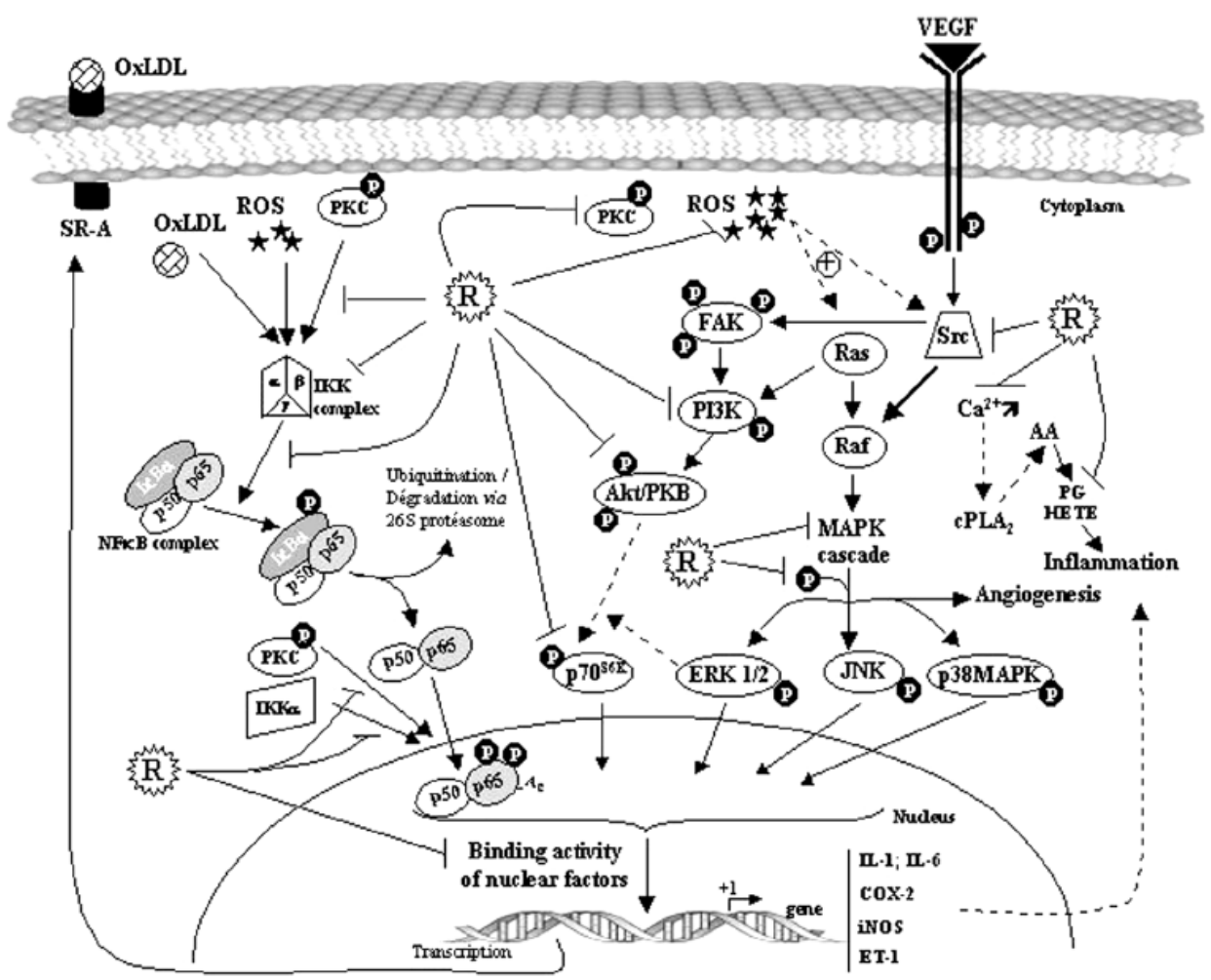

Figure 5. Resveratrol effects on signaling pathways. Resveratrol inhibits VEGF-induced angiogenesis by disruption of ROSdependent Src kinase activation. By this action on Src and MAPK cascade, resveratrol inhibits angiogenesis and the translocation of nuclear factors into the nucleus from the cytoplasm. Moreover, resveratrol inhibits exogenous oxidants, calcium flux, and synthesis of pro-inflammatory compounds. The polyphenol can also inhibit stimuli involved in the activation of NF $\mathrm{NB}$ pathway, such as $\mathrm{PKC} \alpha$ signal transduction, IкB phosphorylation, IKK activity, and p50/p65 nuclear translocation. These effects on the signaling pathways lead to a downregulation of many gene transcription (COX-2, iNOS, VACM, SR-A, etc.) involved in atherosclerotic process and inflammation. 